\title{
Efficient Kidney Exchange: Coincidence of Wants in a Markets with Compatibility-Based Preferences
}

\section{Citation}

Roth, Alvin E., Tayfun Sönmez and M. Utku Ünver. 2007. Efficient Kidney Exchange: Coincidence of Wants in a Markets with Compatibility-Based Preferences. American Economic Review 97(3): 828-851.

\section{Published Version}

http://www.aeaweb.org/articles.php?doi=10.1257/aer.97.3.828;http://dx.doi.org/10.1257/ aer.97.3.828

\section{Permanent link}

http://nrs.harvard.edu/urn-3:HUL.InstRepos:2562809

\section{Terms of Use}

This article was downloaded from Harvard University's DASH repository, and is made available under the terms and conditions applicable to Other Posted Material, as set forth at http:// nrs.harvard.edu/urn-3:HUL.InstRepos:dash.current.terms-of-use\#LAA

\section{Share Your Story}

The Harvard community has made this article openly available.

Please share how this access benefits you. Submit a story.

\section{Accessibility}




\title{
Efficient Kidney Exchange: Coincidence of Wants in Markets with Compatibility-Based Preferences
}

\author{
By Alvin E. Roth, TAYFun SÖNMEZ, AND M. UtKu ÜnVER*
}

\begin{abstract}
Patients needing kidney transplants may have donors who cannot donate to them because of blood or tissue incompatibility. Incompatible patient-donor pairs can exchange donor kidneys with other pairs only when there is a "double coincidence of wants." Developing infrastructure to perform three-way as well as two-way exchanges will have a substantial effect on the number of transplants that can be arranged. Larger than three-way exchanges have less impact on efficiency. In a general model of type-compatible exchanges, the size of the largest exchanges required to achieve efficiency equals the number of types. (JEL C78, I12)
\end{abstract}

In 2005 there were just over 9,900 transplants of deceased donor kidneys for the over 60,000 patients waiting for such transplants in the United States, with a median waiting time of over three years. While waiting, over 4,000 patients died, and another 1,000 were removed from the list when they became "too sick to

\footnotetext{
* Roth: Department of Economics, Harvard University, Cambridge, MA 02138 and Harvard Business School, Boston, MA 02163 (e-mail: al_roth@harvard.edu); Sönmez: Department of Economics, Boston College, Chestnut Hill, MA 02467 (e-mail: sonmezt@bc.edu); Ünver: Department of Economics, University of Pittsburgh, Pittsburgh, PA 15260 (e-mail: uunver@pitt.edu). We would like to thank Audrey Bohnengel, Kevin Cheung, Francis Delmonico, Michel Goemans, Selçuk Karabati, Jonathan Kopke, Jordi Massó, Michael Rees, Susan Saidman, Jun Wako, and Steve Woodle for discussions and comments, and seminar participants at Autonoma Barcelona, Berkeley, CED 2006 at Bodrum, HEC Paris, NBER-CEPR 2005 Workshop at Sabanci, and Vanderbilt University for comments, Rui Dong for her research assistance, and Hüseyin Çankaya for his assistance on drawing the figures. Roth acknowledges the research support of National Science Foundation grant SES0616733, Sönmez acknowledges the research support of the KoçBank scholar program, the Turkish Academy of Sciences Distinguished Young Scholar Award Program, and NSF grant SES-0616470, and Ünver acknowledges the research support of the Turkish Academy of Sciences Distinguished Young Scholar Award Program and NSF grant SES-0616689. A previous version of this paper was entitled "Efficient Kidney Exchange: Coincidence of Wants in a Structured Market." This version of the paper benefits from unusually helpful referee reports. Any errors are our own responsibility.
}

transplant." There were also 6,563 kidney transplants from living donors. ${ }^{1}$

A patient is often unable to receive a willing live-donor's kidney, because of blood-type incompatibility or antibodies to one of the donor's proteins ("positive crossmatch"). Recently a few "paired kidney donations" have been performed between two such incompatible patientdonor pairs: the donor in each pair gives a kidney to the other pair's compatible patient. The National Organ Transplant Act of 1984 makes it illegal to buy or sell a kidney, and so incompatible patient donor pairs are faced squarely with William S. Jevons's classic problem of the "double coincidence of wants":

The first difficulty in barter is to find two persons whose disposable possessions mutually suit each other's wants. There may be many people wanting, and many possessing those things wanted; but to allow of an act of barter, there must be a double coincidence, which will rarely happen. ... The owner of a house may find it unsuitable, and may have his eye upon another house exactly fitted to his needs. But even if the owner of this second

\footnotetext{
${ }^{1}$ The U.S. Scientific Registry of Transplant Recipients (http://www.ustransplant.org/) and the Organ Procurement and Transplantation Network (http://www.optn.org/data/). Live donation of kidneys is possible because people have two kidneys, and healthy people suffer little risk from donating one.
} 
house wishes to part with it at all, it is exceedingly unlikely that he will exactly reciprocate the feelings of the first owner, and wish to barter houses. Sellers and purchasers can only be made to fit by the use of some commodity ... which all are willing to receive for a time, so that what is obtained by sale in one case, may be used in purchase in another. This common commodity is called a medium, of exchange, because it forms a third or intermediate term in all acts of commerce. (Jevons, 1876, chap. 1)

Partly because of the difficulty of finding these double coincidences, there had been few such exchanges: in the fourteen transplant centers in New England (the United Network for Organ Sharing-UNOS-region 1), five such two-way exchanges had been conducted as of December 2004 (cf. Francis L. Delmonico 2004). There had also been a very few threeway exchanges (M. Lucan et al. 2003), ${ }^{2}$ two in the United States by Dr. Robert Montgomery's program at Johns Hopkins (Montgomery et al. 2005). For incentive reasons, all surgeries in an exchange are done simultaneously (so two-way exchange requires four simultaneous surgeries, and three-way requires six). Larger exchanges pose more logistical difficulties.

One theme of the present paper is that some of the difficulties that Jevons attributes to the absence of a medium of exchange will also loom large whenever a thick market is lacking. Even with a medium of exchange, Jevons's second house owner would be reluctant to part with his house if no suitable third house could be found. And we will show that, even without a medium of exchange, if the market is thick enough, the problem of the coincidence of wants can be substantially ameliorated by the organization of an appropriate clearinghouse.

One reason there had been so few exchanges is that until recently there have been no databases of incompatible patient-donor pairs: incompatible donors were simply not further

\footnotetext{
${ }^{2}$ In a three-way exchange, the donor from one pair gives a kidney to the patient of a second pair, whose donor gives to the patient in a third pair, whose donor gives to the patient in the first pair.
}

considered. This is starting to change. In September 2004, the New England Program for Kidney Exchange, proposed by Drs. Delmonico, Susan Saidman, and the three authors of this paper, was approved by the Renal Transplant Oversight Committee of New England. (It is administered through the New England Organ Bank.) Databases for identifying kidney exchanges have also been initiated in Ohio and Baltimore, Maryland. As these exchange programs start to open their doors to patient-donor pairs, one of the primary tasks is to design a clearinghouse that can identify efficient sets of feasible exchanges among incompatible patientdonor pairs (cf. Roth, Sönmez, and Ünver 2004, 2005a, b; Dorry Segev et al. 2005; Roth et al. 2006).

The "coincidence of wants" for kidney exchange has a structure determined in part by the blood types of the patients and donors. Consequently, it is possible to bring simple theory to bear on the question of how efficient such exchange can be, operating just as a gift exchange, in the absence of any medium of exchange. ${ }^{3}$ Computational results on real and simulated patient data (Susan L. Saidman et al. 2006) suggest that as the available population of incompatible patient-donor pairs grows, an increasing percentage of patients will be able to receive a transplant via a two-way exchange, that three-way exchanges will continue to be important for achieving efficient exchange, and that most of the efficiency gains from exchanges larger than two-way are captured by including three-way exchanges. ${ }^{4}$ In the present paper we explore why this is the case. That is, we investigate the structure of efficient exchange, without a medium of exchange, when supply and demand are mediated by blood types.

Furthermore, we will prove that, under the conditions of supply and demand that can normally

\footnotetext{
${ }^{3}$ There is also a literature devoted to the discussion of whether the ban on the buying and selling of kidneys should be repealed. See, e.g., Gary S. Becker and Julio J. Elias (2007) and the survey of this literature in Mark S. Nadel and Caroline A. Nadel (2005) and also Roth (2007).

${ }^{4}$ We have recently been able to confirm this on a database of patient-donor pairs assembled in Ohio by Dr. Steve Woodle, Dr. Michael Rees, Jonathan Kopke, and their colleagues in the Paired Donation Kidney Consortium.
} 
be expected in a population of incompatible patient-donor pairs available for exchange, if we abstract away from tissue-type incompatibilities and look at only the barriers to exchange caused by blood-type incompatibilities, all efficient exchanges can be accomplished in exchanges involving no more than four incompatible pairs. This turns out to be a result that applies quite generally when exchange requires compatibility among agents of different types. We will develop some of the implications for more general typespecific exchange, including situations in which money might also be available as a medium of exchange.

\section{Background}

There are four blood types, A, B, AB, and $\mathrm{O}$ (corresponding to the presence of proteins $\mathrm{A}$ or $\mathrm{B}$, or both together, or neither) and blood-type incompatibility has a very well-defined structure: a patient may not receive the kidney of a donor whose blood contains one of the A or B proteins that the patient does not have. Thus, patients with blood-type $\mathrm{O}$ can receive a kidney only from an $\mathrm{O}$ donor, type $\mathrm{A}$ patients can receive $\mathrm{A}$ or $\mathrm{O}$ kidneys, $\mathrm{B}$ patients $\mathrm{B}$ or $\mathrm{O}$ kidneys, and $\mathrm{AB}$ patients can receive a kidney from a donor of any blood type. Note that a patient with blood-type $\mathrm{O}$ has the most difficulty finding a compatible donor, while $\mathrm{O}$ donors will never have a blood-type incompatibility with any patient.

Tissue-type incompatibility ("positive crossmatch") is much less structured and has to do with the patient having preformed antibodies against one of the donor's proteins. Antibodies can arise from exposure to foreign proteins, e.g., through prior transplants, blood transfusions, or even childbirth. (Consequently, mothers are less likely to be compatible with a kidney from the father of their children than from a random donor from the same population.)

An example helps illustrate why three-way exchange is important. Consider a population of nine incompatible patient-donor pairs. (A pair is denoted as type $\mathrm{X}-\mathrm{Y}$ if the patient and donor are $\mathrm{ABO}$ blood-types $\mathrm{X}$ and $\mathrm{Y}$, respectively.)

Example: There are five pairs of patients who are blood-type incompatible with their donors, of types O-A, O-B, A-B, A-B, and B-A; and four pairs who are incompatible because of positive crossmatch, of types A-A, A-A, A-A, and B-O. For simplicity, in this example there are no positive crossmatches between patients and other patients' donors.

Then six transplants can result from the three possible two-way exchanges, namely (A-B, B-A); (A-A, A-A); (B-O, O-B), where, e.g., (A-B, B-A) denotes an exchange in which a pair of type (A-B) donates a B kidney to the patient in the pair of type (B-A) and receives an A kidney from the donor in that pair. When only two-way exchanges are feasible, these three exchanges constitute a maximal set of exchanges: no other way of arranging exchanges would result in more than six transplants. But if threeway exchanges are also feasible, then eight transplants can be arranged via 1 two-way exchange and 2 three-way exchanges: (A-B, B-A); (A-A, A-A, A-A); (B-O, O-A, A-B). (In the three-way exchanges, the donor in the first pair donates to the patient in the second pair, the second donor donates to the third patient, and the third donor to the first patient, e.g., in the third exchange, the $\mathrm{O}$ donor from the $\mathrm{B}-\mathrm{O}$ pair donates to the $\mathrm{O}$ patient of the $\mathrm{O}-\mathrm{A}$ pair, etc.).

The three-way exchanges allow:

- An odd number of A-A pairs to be transplanted (instead of only an even number with two-way exchanges); and

- An O donor to facilitate three transplants rather than only two.

While the difference between even and odd numbers of pairs will become proportionately smaller as the population of incompatible pairs grows, the importance of making good use of $\mathrm{O}$ donors will remain. O donors will be relatively rare among incompatible patient-donor pairs, because $\mathrm{O}$ donors are only incompatible with their intended recipient if there is a positive crossmatch.

In this example, the only positive crossmatches were between patients and their own donors, but in actual populations there will be positive crossmatches between patients and other donors, particularly since a patient with a positive crossmatch with his own donor is more likely than average to be a highly sensitized 
patient who has antibodies to proteins in a high percentage of potential donors. In such a case, there may be more configurations in which a three-way exchange will be helpful. For instance, suppose in our example the two-way exchange (A-B, B-A) had been infeasible because of a positive crossmatch between the A patient in the first pair and the A donor in the second pair. A three-way exchange (A-B, B-A, A-A) might nevertheless be possible, using one of the A-A pairs. However, the case in which there are only blood-type incompatibilities (and no positive crossmatches) between patients and donors other than their own will allow us to establish an upper bound on the number of exchanges that are possible, since the presence of positive crossmatches can only reduce the set of feasible exchanges.

\section{A Model of Kidney Exchange}

There are a number of kidney patients, each with an incompatible living donor. The incompatibility can be either a blood-type incompatibility or a tissue-type incompatibility (a positive crossmatch). Our emphasis is maximal-size kidney exchanges between patients with incompatible donors. This exercise is especially plausible when patients are indifferent between compatible kidneys. While this is a highly debated topic in the transplantation literature, it is the dominant view among our medical colleagues at the New England Program for Kidney Exchange, based on research that suggests transplants of compatible living donor kidneys have about equal graft survival rates regardless of the closeness of the tissue types between patient and donor (Delmonico 2004; David W. Gjertson and J. Michael Cecka 2000). ${ }^{5}$

A two-way kidney exchange involves two patients, each of whom is incompatible with her own donor but compatible with the other donor. When the two-way exchange is carried out, both patients receive a kidney from the other's donor. A three-way kidney exchange involves three patients, $i, j, k$, each of whom is incom-

\footnotetext{
${ }^{5}$ The topic is controversial because there is also research that suggests that the graft survival rate increases as the tissue type mismatch decreases. See Gerhard Opelz (1997, 1998).
}

patible with her own donor but such that patient $i$ is compatible with the donor of patient $j$, patient $j$ is compatible with the donor of patient $k$, and patient $k$ is compatible with the donor of patient $i$. As in the case of two-way exchange, each patient involved in the trade receives a compatible kidney as a result of the three-way kidney exchange. A four-way kidney exchange is defined similarly.

While patients can have tissue-type incompatibility with their own donors, to establish an upper bound on the number of possible exchanges we will assume that:

ASSUMPTION 1 (upper-bound assumption): No patient is tissue-type incompatible with another patient's donor. ${ }^{6}$

We will derive analytical expressions for the maximum number of patients who can benefit from a feasible set of kidney exchanges among a large population of incompatible pairs, when the only constraints on exchange are imposed by (a) blood-type incompatibility, and (b) the number of patients allowed in each exchange.

Given the "upper bound" assumption, whether a patient can be part of a given exchange depends on her own blood type together with her donor's blood type. When we speak of a type $\mathrm{A}-\mathrm{AB}$ patient-donor pair, we mean a patient-donor pair in which the patient is of blood-type A while her incompatible donor is of blood-type AB. The number of type A-AB patient-donor pairs will be denoted by \#(A-AB). We use analogous notation for all 16 types of patient-donor pairs. We refer to type A-B pairs and type B-A pairs as opposite types, and use the same terminology for other types as well.

Patients with blood-type $\mathrm{O}$ will be incompatible with their donors unless the donor also has blood-type $\mathrm{O}$, and donors with blood-type $\mathrm{AB}$

\footnotetext{
${ }^{6}$ When we later dispense with this assumption to consider populations with the tissue-type incompatibilities found in the national patient population, we will see that, in large markets, this assumption isn't very consequential. The reason is that, although a patient who is tissue-type incompatible with her own donor will likely have positive crossmatches with some other patients' donors also, in a sufficiently large population there will also be many donors with whom she has no tissue-type incompatibility.
} 
will be incompatible with their intended recipient unless she also is AB. So pairs of these types will be overrepresented in populations of incompatible patient-donor pairs. And, when exchanges are carried out, there will be higher demand for $\mathrm{O}$ kidneys than $\mathrm{A}$ kidneys and higher demand for A kidneys than AB kidneys. Similarly, there will be higher demand for $O$ kidneys than B kidneys and higher demand for $B$ kidneys than $A B$ kidneys. This puts pairs of types $\mathrm{O}-\mathrm{A}, \mathrm{O}-\mathrm{B}, \mathrm{O}-\mathrm{AB}, \mathrm{A}-\mathrm{AB}$, and $\mathrm{B}-\mathrm{AB}$ at a disadvantage since they need a kidney that is in higher demand than the kidney they offer. So these type pairs will both occur more frequently and wait longer for an exchange than other types. Therefore, the following is a natural assumption on any sufficiently large population of incompatible patient-donor pairs.

ASSUMPTION 2 (large population of incompatible patient-donor pairs): Regardless of the maximum number of pairs allowed in each exchange, pairs of types $O-A, O-B, O-A B, A-A B$, and $B-A B$ are on the "long side" of the exchange in the sense that at least one pair of each type remains unmatched in each feasible set of exchanges. ${ }^{7}$

\section{A. Maximal-Size Two-Way Exchange}

For any nonnegative number $k$, let $\lfloor k\rfloor$ denote the integer part of $k$, i.e., the greatest integer no larger than $k$.

PROPOSITION 1: For any patient population obeying Assumptions 1 and 2, the maximum

\footnotetext{
${ }^{7}$ It is worth emphasizing that this assumption will characterize large populations of incompatible patient-donor pairs, not patient-donor pairs in general. When we look at the whole population of patient-donor pairs (including the compatible pairs), there will in general be as many $\mathrm{O}$ donors as $\mathrm{O}$ patients. Note also that, in populations in which Assumption 2 is met, there will always be difficult choices to make about which $\mathrm{O}$ patients should receive the scarce $\mathrm{O}$ kidneys, even when attention is confined to maximal sets of exchanges. In game-theoretic terms, the strong core (the core defined by weak domination) of this market, in which many kidneys are equally desirable, is empty (cf. Lloyd Shapley and Herbert Scarf 1974; Roth and Andrew Postlewaite 1977; Thomas Quint and Jun Wako 2004).
}

number of patients who can be matched with only two-way exchanges is

$$
\begin{gathered}
2(\#(\mathrm{~A}-\mathrm{O})+\#(\mathrm{~B}-\mathrm{O})+\#(\mathrm{AB}-\mathrm{O})+\#(\mathrm{AB}-\mathrm{A}) \\
+\#(\mathrm{AB}-\mathrm{B}))+(\#(\mathrm{~A}-\mathrm{B})+\#(\mathrm{~B}-\mathrm{A}) \\
-|\#(\mathrm{~A}-\mathrm{B})-\#(\mathrm{~B}-\mathrm{A})|)+2\left(\left\lfloor\frac{\#(\mathrm{~A}-\mathrm{A})}{2}\right\rfloor\right. \\
\left.+\left\lfloor\frac{\#(\mathrm{~B}-\mathrm{B})}{2}\right\rfloor+\left\lfloor\frac{\#(\mathrm{O}-\mathrm{O})}{2}\right\rfloor+\left\lfloor\frac{\#(\mathrm{AB}-\mathrm{AB})}{2}\right\rfloor\right) .
\end{gathered}
$$

\section{PROOF:}

Each pair of type A-O is compatible with each pair of type O-A by Assumption 1, and types $\mathrm{O}-\mathrm{A}$ are on the long side of the exchange by Assumption 2. Therefore, each pair of type A-O (demanding a kidney that is less sought after than the one they provide) makes a twoway exchange possible. Moreover, since only two-way exchanges are allowed, matching the A-O pair with a pair of a type other than O-A does not increase the size of the maximal set of exchanges. The same argument follows for each pair of types $\mathrm{B}-\mathrm{O}, \mathrm{AB}-\mathrm{O}, \mathrm{AB}-\mathrm{A}$, and $\mathrm{AB}-\mathrm{B}$, explaining the term

$$
\begin{aligned}
2(\#(\mathrm{~A}-\mathrm{O})+\#(\mathrm{~B}-\mathrm{O})+\#(\mathrm{AB}-\mathrm{O}) \\
+\#(\mathrm{AB}-\mathrm{A})+\#(\mathrm{AB}-\mathrm{B})) .
\end{aligned}
$$

Now consider any maximal size match in which every pair of types A-O, B-O, AB-O, AB-A, $A B-B$ is matched with a pair of the opposite type. In the absence of any remaining types $\mathrm{A}-\mathrm{O}, \mathrm{B}-\mathrm{O}, \mathrm{AB}-\mathrm{O}, \mathrm{AB}-\mathrm{A}, \mathrm{AB}-\mathrm{B}$, pairs of types $\mathrm{A}-\mathrm{B}$ and $\mathrm{B}-\mathrm{A}$ can be matched only with a pair of the opposite type. Therefore, unless the two types have the same number of pairs, the longer side will have some pairs that remain unmatched. Since each pair on the shorter side can be matched with a pair on the longer side, \#(A-B) - \#(B-A)| pairs of types A-B, B-A remain unmatched under this maximal size set of exchanges, explaining the second term

$$
(\#(\mathrm{~A}-\mathrm{B})+\#(\mathrm{~B}-\mathrm{A})-|\#(\mathrm{~A}-\mathrm{B})-\#(\mathrm{~B}-\mathrm{A})|) .
$$

Finally when pairs of types A-O, B-O, AB-O, 
$P A I R 1$

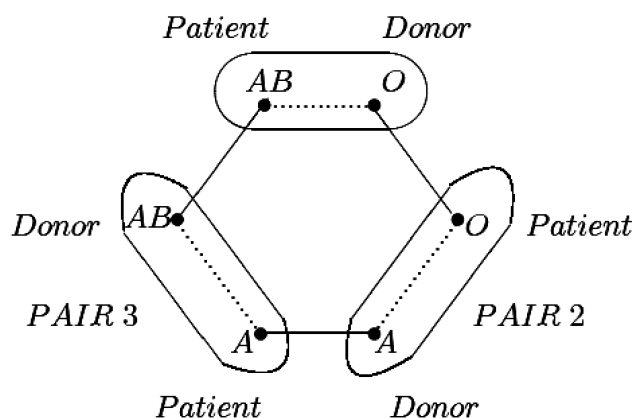

$P A I R 1$

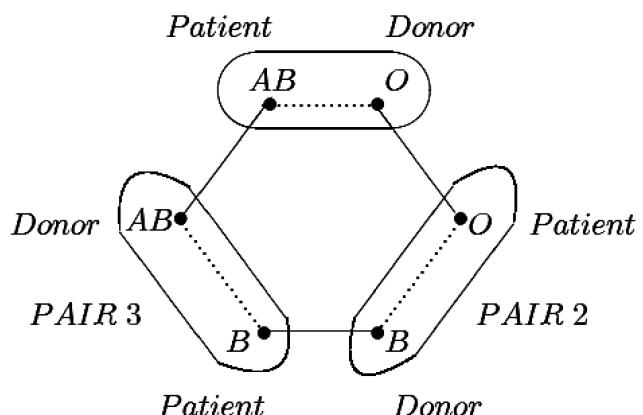

FIGURE 1

Note: When three-way exchanges are feasible, each type AB-O pair can form a three-way exchange with two pairs on the long side.

AB-A, AB-B are each matched with a pair of the opposite type, each pair of types A-A, B-B, $\mathrm{AB}-\mathrm{AB}, \mathrm{O}-\mathrm{O}$ can be matched only with a pair of the same type. Therefore, since only two-way exchanges are allowed, all pairs of type A-A can be matched whenever \#(A-A) is even, and all but one can be matched whenever \#(A-A) is odd. The same argument follows for pairs of types $\mathrm{B}-\mathrm{B}, \mathrm{AB}-\mathrm{AB}, \mathrm{O}-\mathrm{O}$ as well, explaining the last term

$$
\begin{array}{r}
2\left\lfloor\left\lfloor\frac{\#(\mathrm{~A}-\mathrm{A})}{2}\right\rfloor+\left\lfloor\frac{\#(\mathrm{~B}-\mathrm{B})}{2}\right\rfloor+\left\lfloor\frac{\#(\mathrm{O}-\mathrm{O})}{2}\right\rfloor\right. \\
\left.+\left\lfloor\frac{\#(\mathrm{AB}-\mathrm{AB})}{2}\right\rfloor\right) .
\end{array}
$$

\section{B. Maximal-Size Two-Way and Three-Way Exchange}

While two-way kidney exchanges can capture most of the gains from exchange, they cannot capture all potential gains; at least some three-way exchanges are needed. There are several reasons for this:

- Recall that when only two-way exchanges are allowed, one pair of type A-A remains unmatched if \#(A-A) is odd. There is a similar potential efficiency loss for each of the types
B-B, AB-AB, and O-O. For almost all patient populations, that efficiency loss can be avoided once three-way exchanges are allowed. For example, unless there is only one type A-A pair, all type A-A pairs can be matched with each other through one three-way exchange and twoway exchanges for the others. Even when there is only one type A-A pair, she can be "appended" to a two-way exchange between an A-B pair and a B-A pair to form a three-way (B-A, A-A, A-B) exchange.

- With only two-way exchanges, under a maximal size match, each type AB-O pair (with a rare $\mathrm{O}$ donor) is matched with a pair of one of the types $\mathrm{O}-\mathrm{AB}, \mathrm{O}-\mathrm{A}$, or $\mathrm{O}-\mathrm{B}$, each of which is on the long side by Assumption 2. If threeway exchanges are allowed, each type AB-O pair can trade with not one but two pairs on the long side through either an $(\mathrm{AB}-\mathrm{O}, \mathrm{O}-\mathrm{A}$, $\mathrm{A}-\mathrm{AB})$ exchange or an (AB-O, O-B, B-AB) exchange. That increases the size of the maximal-size matching by one for each type AB-O pair (see Figure 1).

- With only two-way exchanges, pairs of types $\mathrm{A}-\mathrm{B}$ and $\mathrm{B}-\mathrm{A}$ can be matched with each other, but $|\#(\mathrm{~A}-\mathrm{B})-\#(\mathrm{~B}-\mathrm{A})|$ pairs on the longer side remain unmatched. With threeway exchanges available, part or all of these $|\#(A-B)-\#(B-A)|$ pairs on the long side can also be matched, increasing the size of the maximal-size set of exchanges. Paul I. Terasaki, Gjertson, and Cecka (1998) report that the frequency of types A-B and B-A are 0.05 
$P A I R 1$

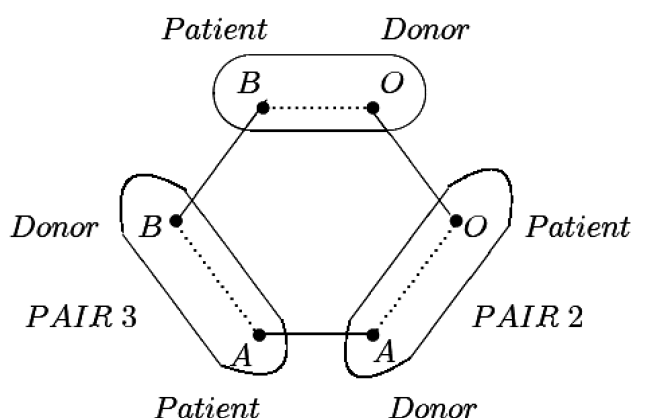

$P A I R 1$

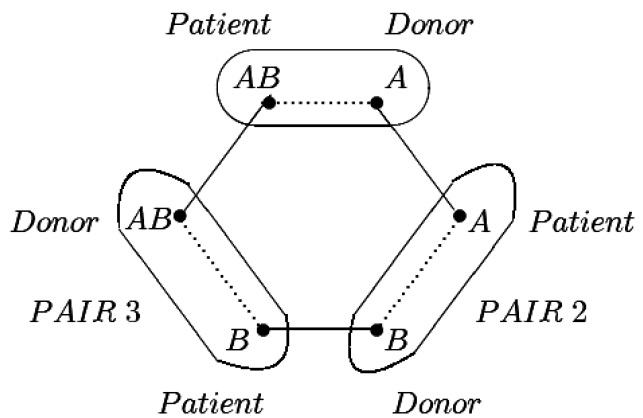

FIGURE 2

Notes: When three-way exchanges are feasible and \#(A-B) $>\#(\mathrm{~B}-\mathrm{A})$, each type B-O pair can form a three-way exchange with two pairs on the long side. The same is also true for each type AB-A pair.

and 0.03 , respectively. So without loss of generality assume that:

ASSUMPTION 3: \#(A-B) > \#(B-A).

Consider a type B-O pair. In the absence of three-way exchanges, each such pair can be matched with one pair on the long side (such as a pair of the opposite type). When three-way exchanges are available, however, a type B-O pair can form a three-way (B-O, O-A, A-B) exchange together with two pairs, each of which is on the long side by Assumptions 2 and 3 . Similarly, while a type AB-A pair can be matched with one pair on the long side when only two-way exchanges are available, it can form a three-way (AB-A, A-B, B-AB) exchange together with two pairs, each of which is on the long side by Assumptions 2 and 3 (see Figure 2). ${ }^{8}$

So, of $|\#(A-B)-\#(B-A)|$ type A-B pairs who remain unmatched under two-way exchanges, as many as $(\#(\mathrm{~B}-\mathrm{O})+\#(\mathrm{AB}-\mathrm{A}))$ can be matched through three-way exchanges. Therefore, such three-way exchanges increases the size of the maximal-size matching by

$\min \{(\#(\mathrm{~A}-\mathrm{B})-\#(\mathrm{~B}-\mathrm{A}))$,

$$
(\#(\mathrm{~B}-\mathrm{O})+\#(\mathrm{AB}-\mathrm{A}))\} .
$$

\footnotetext{
${ }^{8}$ In case \#(B-A) $>$ \#(A-B) instead, type A-O pairs and AB-B pairs become critical and each such pair can form a three-way exchange with two pairs on the long side.
}

To simplify the formula for the size of the maximal set of exchanges, we assume that none of the types A-A, B-B, AB-AB, and $\mathrm{O}-\mathrm{O}$ has only one pair. As we have already argued, when only one pair is present for any of these types, it can be appended to a two-way exchange, but that considerably complicates the description of the size of the maximal-size set of exchanges.

ASSUMPTION 4: There is either no type A-A pair or there are at least two of them. The same is also true for each of the types $B-B, A B-A B$, and $O-O$.

We are ready to summarize these observations in a proposition.

PROPOSITION 2: For any patient population for which Assumptions 1-4 hold, the maximum number of patients who can be matched with two-way and three-way exchanges is:

$$
\begin{gathered}
2[\#(\mathrm{~A}-\mathrm{O})+\#(\mathrm{~B}-\mathrm{O})+\#(\mathrm{AB}-\mathrm{O})+\#(\mathrm{AB}-\mathrm{A}) \\
+\#(\mathrm{AB}-\mathrm{B})]+[\#(\mathrm{~A}-\mathrm{B})+\#(\mathrm{~B}-\mathrm{A}) \\
-|\#(\mathrm{~A}-\mathrm{B})-\#(\mathrm{~B}-\mathrm{A})|]+[\#(\mathrm{~A}-\mathrm{A})+\#(\mathrm{~B}-\mathrm{B}) \\
+\#(\mathrm{O}-\mathrm{O})+\#(\mathrm{AB}-\mathrm{AB})]+\#(\mathrm{AB}-\mathrm{O}) \\
+\min \{[\#(\mathrm{~A}-\mathrm{B})-\#(\mathrm{~B}-\mathrm{A})], \\
[\#(\mathrm{~B}-\mathrm{O})+\#(\mathrm{AB}-\mathrm{A})]\} .
\end{gathered}
$$


To summarize, the marginal effect of threeway kidney exchanges is

$$
\begin{aligned}
& \#(\mathrm{~A}-\mathrm{A})+\#(\mathrm{~B}-\mathrm{B})+\#(\mathrm{O}-\mathrm{O})+\#(\mathrm{AB}-\mathrm{AB}) \\
&-2\left(\left\lfloor\frac{\#(\mathrm{~A}-\mathrm{A})}{2}\right\rfloor+\left\lfloor\frac{\#(\mathrm{~B}-\mathrm{B})}{2}\right\rfloor+\left\lfloor\frac{\#(\mathrm{O}-\mathrm{O})}{2}\right\rfloor\right. \\
&\left.+\left\lfloor\frac{\#(\mathrm{AB}-\mathrm{AB})}{2}\right\rfloor\right)+\#(\mathrm{AB}-\mathrm{O}) \\
&+\min \{[\#(\mathrm{~A}-\mathrm{B})-\#(\mathrm{~B}-\mathrm{A})], \\
& {[\#(\mathrm{~B}-\mathrm{O})+\#(\mathrm{AB}-\mathrm{A})]\} . }
\end{aligned}
$$

For large patient populations, the aggregate frequency of types $\mathrm{AB}-\mathrm{O}, \mathrm{B}-\mathrm{O}$, and $\mathrm{AB}-\mathrm{A}$, accounts for essentially all gains from three-way exchanges (through the exchanges diagrammed in Figures 1 and 2). In small populations, the initial term, that is, one additional patient matched for each of the types A-A, B-B, AB-AB, and $\mathrm{O}-\mathrm{O}$ with an odd size, might account for a substantial part of the gains.

\section{Maximal-Size Two-Way, Three-Way, and Four-Way Exchange}

We have already shown that each type AB-O can form a three-way exchange with two patients on the long side. In case four-way exchanges are allowed and if three-way exchanges cannot handle the entire difference between types A-B and B-A, a type $\mathrm{AB}-\mathrm{O}$ patient can be matched with three patients on the long side to form a four-way exchange. So if \#(A-B) $>\#(B-A)$ as in Assumption 3 , a type $\mathrm{AB}-\mathrm{O}$ patient can form a four-way (AB-O, O-A, A-B, B-AB) exchange with three patients on the long side increasing the size of the maximal-size match by one (see Figure 3 ).

PROPOSITION 3: For any patient population in which Assumptions 1-4 hold, the maximum number of patients who can be matched with two-way, three-way, and four-way exchanges is

$$
\begin{gathered}
2[\#(\mathrm{~A}-\mathrm{O})+\#(\mathrm{~B}-\mathrm{O})+\#(\mathrm{AB}-\mathrm{O})+\#(\mathrm{AB}-\mathrm{A}) \\
+\#(\mathrm{AB}-\mathrm{B})]+[\#(\mathrm{~A}-\mathrm{B})+\#(\mathrm{~B}-\mathrm{A})
\end{gathered}
$$

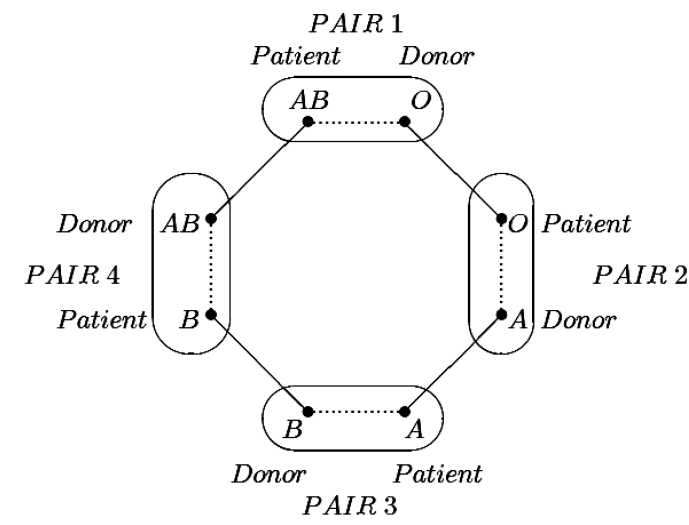

FIGURE 3

Notes: When four-way exchanges are feasible, each type $\mathrm{AB}-\mathrm{O}$ pair can form a four-way exchange with three pairs on the long side.

$$
\begin{gathered}
-|\#(\mathrm{~A}-\mathrm{B})-\#(\mathrm{~B}-\mathrm{A})|]+[\#(\mathrm{~A}-\mathrm{A})+\#(\mathrm{~B}-\mathrm{B}) \\
+\#(\mathrm{O}-\mathrm{O})+\#(\mathrm{AB}-\mathrm{AB})]+\#(\mathrm{AB}-\mathrm{O}) \\
+\min \{[\#(\mathrm{~A}-\mathrm{B})-\#(\mathrm{~B}-\mathrm{A})], \\
[\#(\mathrm{~B}-\mathrm{O})+\#(\mathrm{AB}-\mathrm{A})+\#(\mathrm{AB}-\mathrm{O})]\} .
\end{gathered}
$$

Therefore, in the absence of tissue-type incompatibilities between patients and other patients' donors, the marginal effect of four-way kidney exchanges is bounded above by the rate of the very rare $A B-O$ type.

D. Sufficiency of Two-Way, Three-Way, ..., and $n$-Way Exchange in a General Model of

Type-Compatible Exchange with n Types

So far we have derived analytical expressions for the maximum number of patients who can benefit from kidney exchange when the number of patients allowed in each exchange is no more than two, three, and four. We will next show that given Assumptions 1, 2 , and 4 , the number of patients who can benefit from exchange does not further increase when five-way or larger exchanges are feasible. We will establish this as a corollary of a more general model and result, to clarify that it does not depend on the particular biological features 
of blood types, except for the number of blood types.

\section{A General Model of Type-Specific Exchange} with $n$ Types.

Each pair $i$ consists of a receiving agent $P_{i}$ and a donating agent $D_{i}$. Let $\mathcal{B}$ denote the set of agent types with $|\mathcal{B}|=n>2$ and $\mathcal{T}=\mathcal{B} \times \mathcal{B}$ denote the set of pair types.

Given two agent types $\mathrm{X}, \mathrm{Y} \in \mathcal{B}$,

$$
\mathrm{X} \succeq \mathrm{Y}
$$

is read as $\mathrm{X}$ is compatible with $\mathrm{Y}$ and it means a donating agent of type $X$ can be matched with a receiving agent of type $\mathrm{Y}$. We assume that the compatibility relation $\succeq$ satisfies

$\mathrm{X} \succeq \mathrm{X} \quad$ for any $\mathrm{X} \in \mathcal{B}$, (reflexivity)

$\mathrm{X} \succeq \mathrm{Y}$ and $\mathrm{X} \neq \mathrm{Y} \Rightarrow \mathrm{Y} \nsucceq \mathrm{X}$ for any $\mathrm{X}, \mathrm{Y} \in \mathcal{B}$, (asymmetry)

$\mathrm{X} \succeq \mathrm{Y}$ and $\mathrm{Y} \succeq \mathrm{Z} \Rightarrow \mathrm{X} \succeq \mathrm{Z}$.

(transitivity)

Observe that in the context of kidney exchange, blood-type compatibility satisfies reflexivity, asymmetry, and transitivity. (Note also that the compatibility relation is not a preference ordering, i.e., it may not be complete, as it is not in the case of blood-type compatibility, since neither of blood-types A and B can donate to the other.)

An example of this more general kind of type-specific exchange might be vacation house exchange (of the kind promoted on many Web sites with names containing those words). Each agent is a family-house pair $(\mathrm{X}, \mathrm{Y})$ where $\mathrm{X}$ is a vector that represents family needs in terms of accommodation requirements (e.g., size, number of bedrooms, number of bathrooms) and $\mathrm{Y}$ is a similar vector that corresponds to the characteristics of the house the family has to offer. In this context, $\mathrm{W}$ is compatible with $\mathrm{Z}$ if and only if $\mathrm{W} \geq \mathrm{Z}$. That is, a family with a requirement vector of $Z$ can receive only a house of type $\mathrm{W}$ that meets or exceeds each of its requirements. ${ }^{9}$

In the previous sections we described an exchange through the types of the pairs. Here it is useful to describe an exchange through the identities of the pairs. For example when we speak of a three-way exchange,

$$
E=\left(P_{1}-D_{1}, P_{2}-D_{2}, P_{3}-D_{3}\right),
$$

that means the donating agent $D_{1}$ is matched with the receiving agent $P_{2}$, the donating agent $D_{2}$ is matched with the receiving agent $P_{3}$, and the donating agent $D_{3}$ is matched with the receiving agent $P_{1}$. We refer to any size exchange in a similar way.

An exchange $E$ is feasible if the type of each donating agent in $E$ is compatible with the type of the receiving agent with whom he is matched. A matching is a collection of feasible exchanges such that no pair is part of more than one exchange. A maximal matching is one that includes as many receiver-donor pairs as is feasible, i.e., it is a maximal-size matching.

Assumptions 2 and 4 translate to the present model as follows.

ASSUMPTION 2: Let $\mathrm{X}, \mathrm{Y} \in \mathcal{B}$ be such that $\mathrm{X} \succeq \mathrm{Y}$ and $\mathrm{X} \neq \mathrm{Y}$. Regardless of the maximum number of pairs allowed in each exchange, pairs of type X-Y are on the "long side" of the exchange in the sense that at least one pair of type $\mathrm{X}-\mathrm{Y}$ remains unmatched in each matching.

(Thus, in the housing exchange example, families that seek larger houses than they offer will be in excess supply, just as, in the kidney exchange case, patient-donor pairs seeking a more widely acceptable blood type than they can offer will sometimes remain unmatched.)

ASSUMPTION 4: For any $\mathrm{X} \in \mathcal{B}$, there is either no type $\mathrm{X}-\mathrm{X}$ pair or there are at least two of them.

\footnotetext{
${ }^{9}$ We thank an anonymous referee who suggested extending the model to general types, and who noted that housing exchange in Moscow in the 1970s and 1980s was mostly conducted in pairwise and fairly small exchanges.
} 
Our next result shows that, when the compatibility relation satisfies reflexivity, asymmetry, and transitivity, and the population distribution satisfies Assumptions 2 and 4, exchanges involving more than $n$ pairs are never needed to achieve a maximal size exchange.

THEOREM 1 (n-way exchange suffices): Suppose the compatibility relation satisfies reflexivity, asymmetry, and transitivity. Consider a population for which Assumptions 2 and 4 hold and let $\mu$ be any maximal matching (when there is no restriction on the size of the exchanges that can be included in a matching). Then there exists a maximal matching $\nu$ which consists only of exchanges involving at most $n$ pairs, under which the same set of pairs are matched as in $\mu$.

COROLLARY (4-way exchange suffices in kidney exchange): Consider a patient population for which Assumptions 1, 2, and 4 hold and let $\mu$ be any maximal matching (when there is no restriction on the size of the exchanges that can be included in a matching). Then there exists a maximal matching $\nu$ which consists only of two-way, three-way, and four-way exchanges, under which the same set of patients benefit from exchange as in matching $\mu$.

\section{PROOF OF THEOREM 1:}

Consider a population and a maximal matching $\mu$ as in the statement of the theorem. If $\mu$ is made of $n$-way or smaller exchanges, then we are done. Otherwise, we will construct a matching $\nu$ which is made of $n$-way or smaller exchanges and matches the same set of patients as matching $\mu$.

To simplify the exposition we will prove the theorem for the case in which the largest exchange in matching $\mu$ is $(n+1)$-way. In general, the same proof can be used to show that given any maximal matching in which the largest exchange is of size $k>(n+1)$, there exists another matching which matches the same set of patients through $(k-1)$-way or smaller exchanges; and repeated application of this argument implies the desired result.
Let

$$
\begin{aligned}
E= & \left(P_{1}-D_{1}, P_{2}-D_{2}, P_{3}-D_{3}, \ldots,\right. \\
& \left.P_{n}-D_{n}, P_{n+1}-D_{n+1}\right)
\end{aligned}
$$

be any $(n+1)$-way exchange in $\mu$. We will complete the proof by showing that all pairs in this exchange can be matched via smaller exchanges without changing the set of pairs that are matched.

Since there are $n$ agent types, there are at least two receiving agents in exchange $E$ who are of the same type. Pick any two such receiving agents. We have two cases to consider:

Case 1. Neither of these receiving agents is matched with the donating agent of the other pair under exchange $E$.

Without loss of generality, suppose these receiving agents are $P_{1}$ and $P_{n}$. Under exchange $E$ the receiving agent $P_{1}$ is matched with the donating agent $D_{n+1}$ and the receiving agent $P_{n}$ is matched with the donating agent $D_{n-1}$. Since these two receiving agents are of the same type, each of the donating agents $D_{n-1}$ and $D_{n+1}$ are compatible with either receiving agent and hence the following two exchanges are feasible "dividing" exchange $E$ into two smaller exchanges:

$$
\begin{aligned}
& E^{\prime}=\left(P_{1}-D_{1}, P_{2}-D_{2}, \ldots, P_{n-1}-D_{n-1}\right), \\
& E^{\prime \prime}=\left(P_{n}-D_{n}, P_{n+1}-D_{n+1}\right) .
\end{aligned}
$$

Case 2. At least one of these two receiving agents is matched with the donating agent of the other pair under exchange $E$.

Without loss of generality suppose these receiving agents are $P_{1}$ and $P_{2}$. Since $P_{1}$, who is of the same type as $P_{2}$, is matched with $D_{n+1}$, the type of donating agent $D_{n+1}$ is compatible with the type of the receiving agent $P_{2}$, and hence the $n$-way exchange

$$
\begin{aligned}
E^{*}= & \left(P_{2}-D_{2}, P_{3}-D_{3}, \ldots, P_{n}-D_{n},\right. \\
& \left.P_{n+1}-D_{n+1}\right)
\end{aligned}
$$

is feasible. We will complete the proof by showing that the remaining pair $\left(P_{1}-D_{1}\right)$ can be included in an exchange without affecting pairs that are matched under $\mu$. 
Let pair $\left(P_{1}-D_{1}\right)$ be of type X-Y. By assumption, agents $P_{1}$ and $P_{2}$ are of the same type and therefore $P_{2}$ is of type $\mathrm{X}$. Moreover under exchange $E$ the donating agent $D_{1}$, who is of type Y, is matched with the receiving agent $P_{2}$. Hence $\mathrm{Y}$ $\succeq \mathrm{X}$. We have two cases to consider:

Case $2 a . \mathrm{X} \neq \mathrm{Y}$.

Since $Y \succeq X$ and $X \neq Y$, by Assumption 2 pairs of type $Y-X$ are on the long side of the exchange and there exists a pair of type Y-X who are unmatched under $\mu$. Pair $\left(P_{1}-D_{1}\right)$ can form a two-way exchange with this pair, increasing the total number of pairs that are matched and contradicting that $\mu$ is of maximalsize. Hence this case cannot occur.

Case $2 b . \mathrm{X}=\mathrm{Y}$.

By Assumption 4 there is at least one other pair $\left(P_{n+2}-D_{n+2}\right)$ of the same type (and thus receiving agents $P_{1}, P_{n+2}$ and donating agents $D_{1}, D_{n+2}$ all have the same type). This pair is part of an exchange $\hat{E}$ under $\mu$, for, otherwise, pair $\left(P_{1}-D_{1}\right)$ could form a two-way exchange with them by reflexivity and this would contradict the maximality of matching $\mu$. If $\hat{E}$ involves less than $n$ pairs, then pair $\left(P_{1}-D_{1}\right)$ can be "appended" to this exchange (right before or right after pair $\left.\left(P_{n+2}-D_{n+2}\right)\right)$. If, on the other hand, $\hat{E}$ is a larger exchange, then pair $\left(P_{n+2}-D_{n+2}\right)$ can be removed from $\hat{E}$ to form a two-way exchange with pair $\left(P_{1}-D_{1}\right)$ which is feasible by reflexivity. Moreover, since $P_{n+2}$ and $D_{n+2}$ are of the same type, the transitivity of $\succeq$ implies that the donating agent who is matched with the receiving agent $P_{n+2}$ under $\hat{E}$ can instead be matched with the receiving agent who is matched with the donating agent $D_{n+2}$ under $\hat{E}$, and hence the remaining pairs in $\hat{E}$ can form an exchange with one less pair.

Looking at the role of Assumptions 1, 2, and 4 in the corollary, we can restate it as follows. In a sufficiently large population of incompatible patient-donor pairs, the only reasons that efficient exchange may require exchanges involving more than four pairs are idiosyncratic tissue- type incompatibilities, and the presence of singleton patient-donor pairs with the same blood type. We next consider how much deviation from the results above we should expect in patient populations having the incidence of tissue-type incompatibilities we see in the national patient population.

\section{Simulations Using National Patient Characteristics}

In this section we dispense with the simplifying assumptions made so far and turn to simulated data reflecting national patient characteristics. Specifically, we now look at populations in which a patient may have tissue-type incompatibilities with many donors. This will allow us to see how good are the approximations derived above under the assumption that exchange was limited only by blood-type incompatibilities.

The simulations reported here follow those of Saidman et al. (2006), with the addition that, for each simulated population, we compute not only the actual maximal number of exchanges, but also the predicted (upper bound) number based on the formulas derived above. (These formulas depend on the details of the simulation, insofar as they depend on the number of pairs of each type present in each simulated population.) We will see that the formulae predict the actual number of exchanges surprisingly well. That is, the upper bounds on the maximal number of exchanges when exchange is limited only by blood-type incompatibility are not far above the numbers of exchanges that can actually be realized. In addition, only a small number of exchanges involving more than four pairs are needed to achieve efficiency in the simulated data.

\section{A. Patient-Donor Population Construction}

We consider samples of non-blood-related patient-donor pairs to avoid the complications due to the impact of genetics on immunological incompatibilities. The characteristics such as the blood types of patients and donors, the PRA (percent reactive antibody) distribution of the patients, donor relation of patients, and the gender of the patients are generated using the empirical distributions of the U.S. Organ Procurement and Transplantation Network (OPTN) and the Scientific Registry of Transplant Recipients (SRTR) data (see Table 1). We consider all ethnicities in the data.

In our simulations, we randomly simulate a series of patient-donor pairs using the population characteristics explained above. Whenever 
TABLE 1

\begin{tabular}{lc}
\hline \hline A. Patient ABO blood type & Frequency (percent) \\
\hline O & 48.14 \\
A & 33.73 \\
B & 14.28 \\
AB & 3.85 \\
\hline
\end{tabular}

\begin{tabular}{lc}
\hline B. Patient gender & Frequency (percent) \\
\hline Female & 40.90 \\
Male & 59.10 \\
\hline
\end{tabular}

C. Unrelated living donors

\begin{tabular}{ll}
\hline Spouse & 48.97 \\
Other & 51.03
\end{tabular}

\begin{tabular}{lc}
\hline E. PRA distribution & Frequency (percent) \\
\hline Low PRA & 70.19 \\
Medium PRA & 20.00 \\
High PRA & 9.81
\end{tabular}

Notes: Patient and living donor distributions used in simulations based on OPTN/SRTR Annual Report in 2003, for the period 1993-2002, retrieved from http://www.optn.org on $11 / 22 / 2004$. Patient characteristics are obtained using the new waiting list registrations data, and living donor relational type distribution is obtained from living donor transplants data.

a pair is compatible (both blood-type compatible and tissue-type compatible), the donor can directly donate to the intended recipient and therefore we do not include them in our sample. Only when they are either blood-type or tissuetype incompatible do we keep them, until we reach a sample size of $n$ incompatible pairs. We use a Monte-Carlo simulation size of 500 random population constructions for three population sizes of 25,50 , and $100 .^{10}$

\footnotetext{
${ }^{10}$ Twenty-five to 100 pairs of new arrivals is somewhat optimistic but not unrealistic, especially if a national exchange or multiregional exchanges are established in the United States. Currently in New England, matching is conducted each month and in a month about four to six new pairs are added to the exchange pool. Cooperation among various kidney exchange programs (e.g., New England and New Jersey) is currently being discussed. While the overall efficiency of the system diminishes as the population size gets smaller, the relative importance of three-way exchange increases. Hence our simulations somewhat underrepresent the relative importance of three-way exchange for existing kidney exchange programs.
}

\section{B. Tissue-Type Incompatibility}

Tissue-type incompatibility (a positive crossmatch) is independent of blood-type incompatibility and arises when a patient has preformed antibodies against a donor tissue type.

Patients in the OPTN/SRTR database are divided into the following three groups based on the odds that they have a crossmatch with a random donor:

- Low PRA patients: patients who have a positive crossmatch with less than 10 percent of the population;

- Medium PRA patients: patients who have a positive crossmatch with $10-80$ percent of the population;

- High PRA patients: patients who have a positive crossmatch with more than 80 percent of the population.

Frequencies of low, medium, and high PRA patients reported in the OPTN/SRTR database are given in Table 1. Since a more detailed PRA distribution is unavailable in the medical literature, we will simply assume that:

- Each low PRA patient has a positive crossmatch probability of 5 percent with a random donor;

- Each medium PRA patient has a positive crossmatch probability of 45 percent with a random donor; and

- Each high PRA patient has a positive crossmatch probability of 90 percent with a random donor.

We have already indicated that when a patient is female and the potential donor is her husband, it is more likely that they have a positive crossmatch due to pregnancies. Stefanos Zenios, Woodle, and Laine Friedman Ross (2001) indicate that while positive crossmatch probability is 11.1 percent between random pairs, it is 33.3 percent between female patients and their donor husbands. Equivalently, female patients' negative crossmatch probability (i.e., the odds that there is no tissue-type incompatibility) with their husbands is approximately 75 percent of the negative crossmatch probability with a random donor. Therefore, we accordingly 
adjust the positive crossmatch probability between a female patient and her donor husband using the formula

$$
\mathrm{PRA}^{*}=100-0.75(100-\mathrm{PRA})
$$

and assume that

- Each low PRA female patient has a positive crossmatch probability of 28.75 percent with her husband;

- Each medium PRA female patient has a positive crossmatch probability of 58.75 percent with her husband; and

- Each high PRA female patient has a positive crossmatch probability of 92.25 percent with her husband.

\section{Outline of the Simulations}

For each sample of $n$ incompatible patientdonor pairs, we find the maximum number of patients who can benefit from an exchange when both blood-type and tissue-type incompatibilities are considered, and

- Only two-way exchanges are allowed;

- Two-way and three-way exchanges are allowed;

- Two-way, three-way, and four-way exchanges are allowed; and

- Any size exchange is allowed.

In our simulations, to find the maximal number of patients who can benefit from an exchange when only two-way exchanges are allowed, we use a version of Jack Edmonds's (1965) algorithm (see Roth, Sönmez, and Ünver 2005a), and to find the maximal number of patients who can benefit from an exchange when larger exchanges are allowed, we use various integer programming techniques. We outline this formulation in the Appendix.

We compare these numbers with those implied by the analytical expressions in Propositions $1-3$, to see whether those formulae are close approximations, or merely crude upper bounds. Since many high PRA patients cannot be part of any exchange due to tissue-type incompatibilities, we report two sets of upper bounds induced by the formulae we developed:
- For each sample we use the formulae with the raw data; and

- For each sample we restrict our attention to patients, each of whom can participate in at least one feasible exchange.

That is, in Table 2, "upper bound 1" for each maximal allowable size exchange is the formula developed above for that size exchange (i.e., Propositions 1, 2, and 3 for maximal exchange sizes 2,3 , or 4 pairs) with the population size of $n=25,50$, or 100 . However, in a given sample of size $n=25$, for example, there may be some patients who have no compatible donor, because of tissue-type incompatibilities, and hence cannot possibly participate in an exchange. In this population there is therefore a smaller number $n^{\prime}<n$ of pairs actually available for exchange, and "upper bound 2 " in Table 2 reports the average overall populations for the formulas using this smaller population of incompatible patient-donor pairs. Clearly upper bound 2 provides a more precise (i.e., lower) upper bound to the number of exchanges that can be found. The fact that the difference between the two upper bounds diminishes as the population size increases reflects that, in larger populations, even highly sensitized patients are likely to find a compatible donor.

\section{Discussion of the Simulation Results}

The static simulation results (which include tissue-type incompatibilities) are very similar to the theoretical upper bounds we develop for the case with only blood-type incompatibilities. While two-way exchanges account for most of the potential gains from exchange, the number of patients who benefit from exchange significantly increases when three or more pair exchanges are allowed, and, consistent with the theory, three-way exchanges account for a large share of the remaining potential gains. For example, for a population size of 25 pairs, an average of:

- 11.99 pairs can be matched when any size exchange is feasible;

- 11.27 pairs can be matched when only twoway and three-way exchanges are feasible; and 
TABLE 2

\begin{tabular}{|c|c|c|c|c|c|}
\hline \multirow[b]{2}{*}{$\begin{array}{l}\text { Pop. } \\
\text { size }\end{array}$} & \multirow[b]{2}{*}{ Method } & \multicolumn{4}{|c|}{ Type of exchange } \\
\hline & & Two-way & $\begin{array}{l}\text { Two-way, } \\
\text { three-way }\end{array}$ & $\begin{array}{l}\text { Two-way, } \\
\text { three-way, } \\
\text { four-way }\end{array}$ & $\begin{array}{c}\text { No } \\
\text { constraint }\end{array}$ \\
\hline \multirow{3}{*}{$n=25$} & Simulation & $\begin{array}{l}8.86 \\
(3.4866)\end{array}$ & $\begin{array}{l}11.272 \\
(4.0003)\end{array}$ & $\begin{array}{l}11.824 \\
(3.9886)\end{array}$ & $\begin{array}{l}11.992 \\
(3.9536)\end{array}$ \\
\hline & Upperbound 1 & $\begin{array}{l}12.5 \\
(3.6847)\end{array}$ & $\begin{array}{l}14.634 \\
(3.9552)\end{array}$ & $\begin{array}{l}14.702 \\
(3.9896)\end{array}$ & \\
\hline & Upperbound 2 & $\begin{array}{c}9.812 \\
(3.8599)\end{array}$ & $\begin{array}{l}12.66 \\
(4.3144)\end{array}$ & $\begin{array}{l}12.892 \\
(4.3417)\end{array}$ & \\
\hline \multirow{3}{*}{$n=50$} & Simulation & $\begin{array}{l}21.792 \\
(5.0063)\end{array}$ & $\begin{array}{l}27.266 \\
(5.5133)\end{array}$ & $\begin{array}{l}27.986 \\
(5.4296)\end{array}$ & $\begin{array}{l}28.09 \\
(5.3658)\end{array}$ \\
\hline & Upperbound 1 & $\begin{array}{l}27.1 \\
(5.205)\end{array}$ & $\begin{array}{l}30.47 \\
(5.424)\end{array}$ & $\begin{array}{l}30.574 \\
(5.4073)\end{array}$ & \\
\hline & Upperbound 2 & $\begin{array}{l}23.932 \\
(5.5093)\end{array}$ & $\begin{array}{c}29.136 \\
(5.734)\end{array}$ & $\begin{array}{l}29.458 \\
(5.6724)\end{array}$ & \\
\hline \multirow{3}{*}{$n=100$} & Simulation & $\begin{array}{l}49.708 \\
(7.3353)\end{array}$ & $\begin{array}{l}59.714 \\
(7.432)\end{array}$ & $\begin{array}{l}60.354 \\
(7.3078)\end{array}$ & $\begin{array}{l}60.39 \\
(7.29)\end{array}$ \\
\hline & Upperbound 1 & $\begin{array}{l}56.816 \\
(7.2972)\end{array}$ & $\begin{array}{l}62.048 \\
(7.3508)\end{array}$ & $\begin{array}{l}62.194 \\
(7.3127)\end{array}$ & \\
\hline & Upperbound 2 & $\begin{array}{l}53.496 \\
(7.6214)\end{array}$ & $\begin{array}{l}61.418 \\
(7.5523)\end{array}$ & $\begin{array}{l}61.648 \\
(7.4897)\end{array}$ & \\
\hline
\end{tabular}

Notes: Simulation results about average number of patients actually matched and predicted by the formulae to be matched. The standard errors of the population are reported in parentheses. The standard errors of the averages are obtained by dividing population standard errors by square root of the simulation number, 22.36 .

- 8.86 pairs can be matched when only twoway exchange is feasible.

Hence for $n=25$, two-way exchange accounts for 74 percent (i.e., (8.86/11.99)) of the potential gains from exchange, whereas threeway exchange accounts for 77 percent (i.e., $(11.27-8.86 / 11.99-8.86))$ of the remaining potential gains. These rates are 78 percent and 87 percent for a population size of 50 pairs, and 82 percent and 94 percent for a population size of 100 pairs. The theory developed in the absence of crossmatches is still predictive when there are crossmatches: virtually all possible gains from trade are achieved with two-way, three-way, and four-way exchanges, especially when the population size is large (see Table 2). ${ }^{11}$

\footnotetext{
${ }^{11}$ When the population size is 100 incompatible pairs, in 485 of the 500 simulated populations the maximum possible gains from trade are achieved when no more than four pairs are allowed to participate in an exchange.
}

\section{E. Simulations for Myopic Dynamic Exchange}

The current tendency in various regions of the United States is to implement kidney exchange in a static (batch-process) way, to achieve the efficiencies that result from having a "thick" market. For example, in New England, matching is conducted every month, and in Ohio every two months. Nevertheless there may be kidney exchange programs that consider carrying out exchanges in a dynamic way, as they become available. Intuitively one would expect the importance of three-way exchange to persist: since it is easier to match pairs on the short side of the exchange, there will be an abundance of long-side pairs in the long run. So when a rare $\mathrm{O}$ donor arrives due to tissue-type incompatibility, say an A patient-O donor pair, whether that pair can be utilized via a three-way exchange (as opposed to a two-way exchange with its opposite type) depends on whether there is a compatible B patient-A donor pair in the pool (since there will be an abundance 
Table 3-Dynamic Exchange Simulations: Number of PATIENTS MATCHED

\begin{tabular}{|c|c|c|c|c|}
\hline $\begin{array}{l}\text { Pop. } \\
\text { size }\end{array}$ & Two-way & $\begin{array}{l}\text { Two-way, } \\
\text { three-way }\end{array}$ & $\begin{array}{l}\text { Two-way, } \\
\text { three-way, } \\
\text { four-way }\end{array}$ & $\begin{array}{c}\text { No } \\
\text { constraint }\end{array}$ \\
\hline$n=25$ & $\begin{array}{c}8.30 \\
(3.13)\end{array}$ & $\begin{array}{c}9.56 \\
(3.39)\end{array}$ & $\begin{array}{c}9.87 \\
(3.49)\end{array}$ & $\begin{array}{c}9.97 \\
(3.53)\end{array}$ \\
\hline$n=50$ & $\begin{array}{l}20.28 \\
(4.50)\end{array}$ & $\begin{array}{l}23.27 \\
(4.98)\end{array}$ & $\begin{array}{l}24.03 \\
(5.02)\end{array}$ & $\begin{array}{l}24.30 \\
(5.05)\end{array}$ \\
\hline$n=100$ & $\begin{array}{l}46.09 \\
(6.60)\end{array}$ & $\begin{array}{l}52.39 \\
(6.87)\end{array}$ & $\begin{array}{l}53.80 \\
(6.95)\end{array}$ & $\begin{array}{l}54.36 \\
(6.98)\end{array}$ \\
\hline
\end{tabular}

of $\mathrm{O}$ patient-B donor pairs). This is a likely possibility.

In this section we present myopic dynamic simulations. Pairs enter the pool one at a time and exchanges are carried out as they form. Larger size exchanges are given priority when three or more pair exchanges are feasible. Table 3 summarizes the results. Notice (by comparison with Table 2) that fewer transplants are achieved than when the population of incompatible patientdonor pairs is allowed to accumulate.

The importance of three-way exchange is reduced but still present in the myopic dynamic simulations, and four-way exchange gains importance in comparison with its importance in static simulations (see also Ünver 2007).

\section{Competitive Kidney Exchange: Hypothetical Prices}

The National Organ Transplant Act of 1984 makes it illegal to buy or sell a kidney, or to make monetary transfers among pairs who participate in kidney exchange. However, in other kinds of type-compatible exchanges, such as vacation houses, nothing prevents such supplementary exchanges. And, even in the context of kidney exchange, the hypothetical consideration of competitive prices may help illuminate some issues that are not brought out in the models we consider. One of these is the prospect of enticing compatible pairs (and not just incompatible pairs) to enter into kidney exchange. ${ }^{12}$ Includ-

\footnotetext{
${ }^{12}$ While most of our surgical colleagues treat preferences over kidneys as either 0 or 1 based on compatibility, and we have concentrated on compatibility here and in the organization of actual kidney exchanges, there is some
}

ing compatible pairs would have a big impact on efficiency, i.e., on the total number of additional transplants that could be conducted. In this section we turn our attention to a variant of our model where monetary transfers are possible among pairs and where compatible pairs may participate in exchange if they find it in their best interest. We are fully aware of the ethical arguments against use of monetary transfers in the context of live donation, and our purpose is not to advocate its use. ${ }^{13}$ Nevertheless we would like to understand the interaction between long and short sides of the market in the presence of monetary transfers, as well as how that is reflected in competitive prices. Throughout this section we will consider only two-way exchanges so that it is straightforward to define a competitive equilibrium.

As in earlier sections, a pair of type $X-Y$ has a blood-type $\mathrm{X}$ patient and a blood-type $\mathrm{Y}$ donor. Let $\mathcal{T}=\{\mathrm{O}, \mathrm{A}, \mathrm{B}, \mathrm{AB}\} \times\{\mathrm{O}, \mathrm{A}, \mathrm{B}, \mathrm{AB}\}$ denote the set of all types. Given a pair $i$, let $\mathcal{T}(i)$ denote its type.

To simplify the analysis, we assume there is a continuum of pairs for each type. Let $\#^{I}(\mathrm{X}-\mathrm{Y}) \geq 0$ be the mass of $\mathrm{X}-\mathrm{Y}$ type incompatible pairs and $\#(X-Y) \geq 0$ be the mass of all $\mathrm{X}-\mathrm{Y}$ type pairs. Incompatibility may be due either to blood type or positive crossmatch. Observe that for blood-type-incompatible pairs $\mathrm{X}-\mathrm{Y} \in\{\mathrm{O}-\mathrm{AB}, \mathrm{O}-\mathrm{A}, \mathrm{O}-\mathrm{B}, \mathrm{A}-\mathrm{AB}, \mathrm{A}-\mathrm{B}$, $\mathrm{B}-\mathrm{AB}, \mathrm{B}-\mathrm{A}\}$,

$$
\#(\mathrm{X}-\mathrm{Y})=\#^{I}(\mathrm{X}-\mathrm{Y}) .
$$

We assume each pair $i$ has a valuation $v_{i}$ for exchange and its utility from receiving an ex-

attention given to issues beyond simple compatibility. Thus (while compatible pairs are not yet invited to participate in exchange), one can imagine that a compatible A-O pair whose donor is significantly smaller and older than her intended recipient might benefit from exchange with an incompatible $\mathrm{O}-\mathrm{A}$ pair whose donor is bigger and younger, so that there would be mutual gains from exchange, with the compensation to the compatible pair coming in the form of a somewhat more desirable kidney. And see Richard A. Epstein (2006) for a proposal that actual monetary transfers be facilitated to encourage compatible pairs to enter into exchanges.

${ }^{13}$ For a discussion of repugnance as a constraint on market design, see Roth (2007). 


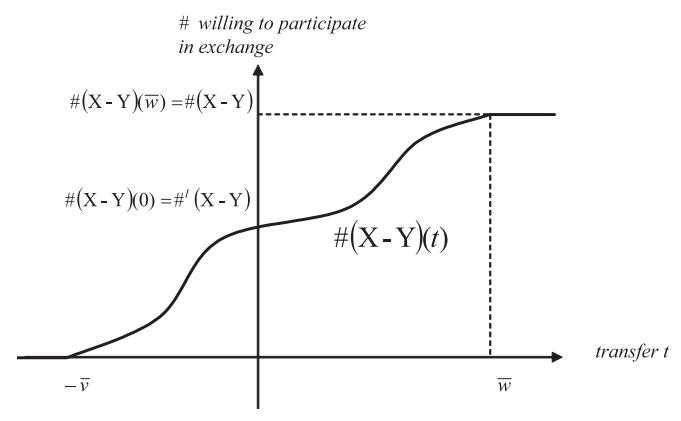

Figure 4. Function \#(X-Y)(·) FOR BlOOd-TyPeCOMPATIBLE TYPE X-Y

change together with a (possibly negative) monetary transfer of $t_{i}$ is

$$
v_{i}+t_{i}
$$

whereas its utility from remaining unmatched is 0 . For each incompatible pair $i$, there is a nonnegative valuation $v_{i} \in[0, \bar{v}]$ for exchange. Each compatible pair $i$, on the other hand, has a nonpositive valuation ${ }^{14} v_{i} \in[-\bar{w}, 0]$ for exchange where $\bar{w} \geq \bar{v}$. We assume there is no atom at any valuation. A pair $i$ prefers exchange with transfer $t_{i}$ to remaining unmatched, if and only if

$$
v_{i}+t_{i} \geq 0 .
$$

For any type X-Y, let $N_{\mathrm{X}-\mathrm{Y}}(t)$ be the set of type $X-Y$ pairs who prefer exchange to remaining unmatched upon receiving a transfer $t$, and let $\#(X-Y)(t)$ be the mass of type $X-Y$ pairs who prefer exchange to remaining unmatched upon receiving a transfer $t$. For a blood-type compatible type $\mathrm{X}-\mathrm{Y}$, function $\#(\mathrm{X}-\mathrm{Y})(\cdot)$ is continuous and strictly increasing in the interval $[-\bar{v}, \bar{w}]$ with

$$
\begin{array}{r}
\#(\mathrm{X}-\mathrm{Y})(-\bar{v})=0, \quad \#(\mathrm{X}-\mathrm{Y})(0)=\#^{I}(\mathrm{X}-\mathrm{Y}) \\
\text { and } \quad \#(\mathrm{X}-\mathrm{Y})(\bar{w})=\#(\mathrm{X}-\mathrm{Y}) .
\end{array}
$$

(See Figure 4.)

\footnotetext{
${ }^{14}$ This models the fact that a compatible pair expects to receive some benefit from undertaking an exchange rather than engaging in a simple live donor transplant from donor to compatible recipient.
}

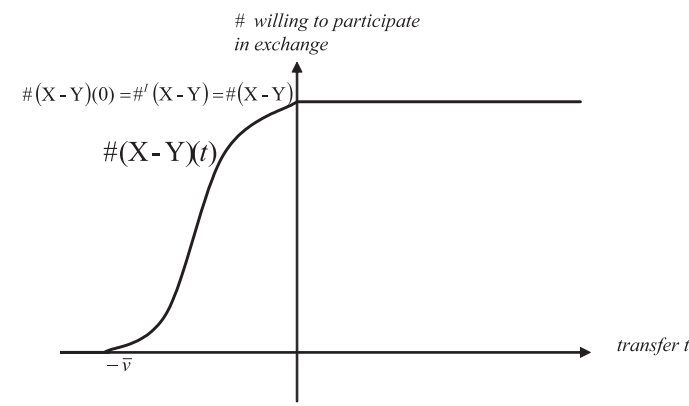

Figure 5. Function \#(X-Y)(.) FOR BLOOD-TyPeINCOMPATIBLE TYPE X-Y

For a blood-type-incompatible type X-Y, function $\#(X-Y)(\cdot)$ is continuous and strictly increasing in the interval $[-\bar{v}, 0]$ with

$$
\begin{aligned}
\#(\mathrm{X}-\mathrm{Y})(-\bar{v})=0 \quad \text { and } & \\
\#(\mathrm{X}-\mathrm{Y})(t)=\#^{I}(\mathrm{X}-\mathrm{Y})=\#(\mathrm{X}-\mathrm{Y}) & \text { for any } t \geq 0 .
\end{aligned}
$$

(See Figure 5.)

For any type $\mathrm{X}-\mathrm{Y}$, let $C(\mathrm{X}-\mathrm{Y})$ be the set of its mutually compatible types. We maintain Assumptions 1, 2, and 3. In the present model, Assumptions 2 and 3 translate as follows:

ASSUMPTION 2: For any type $\mathrm{X}-\mathrm{Y} \in$ $\{\mathrm{O}-\mathrm{AB}, \mathrm{O}-\mathrm{A}, \mathrm{O}-\mathrm{B}, \mathrm{A}-\mathrm{AB}, \mathrm{B}-\mathrm{AB}\}$,

$$
\#(\mathrm{X}-\mathrm{Y})=\#^{I}(\mathrm{X}-\mathrm{Y})>\sum_{\mathrm{W}-\mathrm{Z} \in C(\mathrm{X}-\mathrm{Y})} \#^{I}(\mathrm{~W}-\mathrm{Z}) .
$$

\section{ASSUMPTION 3:}

$$
\#(\mathrm{~A}-\mathrm{B})=\#^{I}(\mathrm{~A}-\mathrm{B})>\#^{I}(\mathrm{~B}-\mathrm{A})=\#(\mathrm{~B}-\mathrm{A}) .
$$

We refer to patient-donor types $S=\{\mathrm{AB}-\mathrm{O}$, $\mathrm{A}-\mathrm{O}, \mathrm{B}-\mathrm{O}, \mathrm{AB}-\mathrm{B}, \mathrm{AB}-\mathrm{A}, \mathrm{B}-\mathrm{A}\}$ as the short side of the market and their opposite types $\mathcal{L}=$ $\{\mathrm{O}-\mathrm{AB}, \mathrm{O}-\mathrm{A}, \mathrm{O}-\mathrm{B}, \mathrm{A}-\mathrm{AB}, \mathrm{B}-\mathrm{AB}, \mathrm{A}-\mathrm{B}\}$ as the long side of the market. Figure 6 shows the mutual compatibilities between the short and long sides of the market. (Note that the mutual compatibilities within the short side, e.g., AB-O and $\mathrm{B}-\mathrm{A}$, are not represented in the figure.) As 


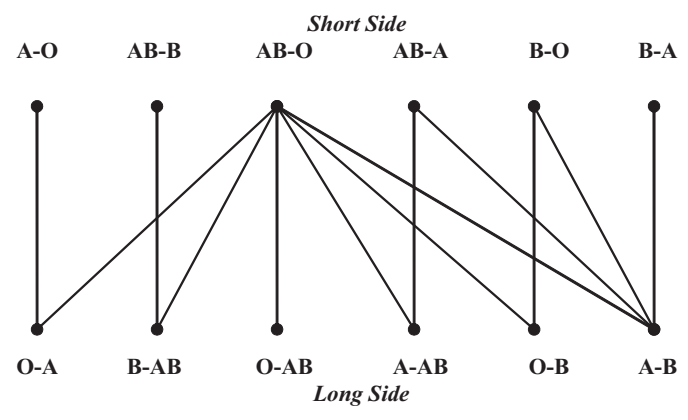

FIGURE 6

Notes: Mutual compatibility between long and short sides of the market under Assumptions 1, 2, and 3.

a direct implication of Proposition 4, short-side pairs will be matched only with long-side pairs at competitive equilibrium.

A matching $\mu$ is a set of two-way exchanges such that no pair participates in two distinct exchanges. Pair $i$ is unmatched under $\mu$ if $\mu(i)=$ $i$ and it is matched if $\mu(i) \neq i$. $\mathbb{R}^{|\mathcal{T}|}$.

A price vector is a list $p=\left(p_{\mathrm{X}-\mathrm{Y}}\right)_{\mathrm{X}-\mathrm{Y} \in \mathcal{T}} \in$

A competitive equilibrium is a matchingprice vector pair $(\mu, p)$ such that:

1. For any matched pair $i$,

(a) $p_{\mathcal{T}_{(i)}}+p_{\mathcal{T}_{(\mu(i))}}=0$ (balanced budget);

(b) $v_{i}-p_{\mathcal{T}(\mu(i))}=v_{i}+p_{\mathcal{T}(i)} \geq 0$ (individual rationality);

(c) $v_{i}-p_{\mathcal{T}(\mu(i))}=v_{i}+p_{\mathcal{T}(i)} \geq v_{i}-p_{X-Y}$ for any $\mathrm{X}-\mathrm{Y} \in C(\mathcal{T}(i)) \quad$ (utility maximization).

2. For any unmatched pair $i, 0 \geq v_{i}+p_{\mathcal{T}(i)}$ and $0 \geq v_{i}-p_{\mathrm{X}-\mathrm{Y}}$ for any $\mathrm{X}-\mathrm{Y} \in C(\mathcal{T}(i))$ (utility maximization).

Let $(\mu, p)$ be a competitive equilibrium. For any pair $i$, its utility at $(\mu, p)$ is $\max \left\{0, v_{i}+p_{\mathcal{T}(i)}\right\}$. Moreover, for each type $\mathrm{X}-\mathrm{Y}, N_{\mathrm{X}-\mathrm{Y}}\left(p_{\mathrm{X}-\mathrm{Y}}\right)$ is the set of pairs matched under $\mu$ and $\#(X-Y)\left(p_{X-Y}\right)$ is the mass of pairs matched under $\mu$.

\section{A. Competitive Prices}

Our next result serves a number of purposes. First, it shows that pairs of types on the short side receive positive transfers at competitive equilibrium at the expense of pairs of types on the long side. All incompatible pairs of shortside types are matched at competitive equilibrium (as is the case without money under a maximal set of exchanges), and additionally market clearing prices are set to bring sufficient numbers of compatible pairs of short-side types into the market (except for type B-A). Second, it shows that pairs of types that are critical for increased efficiency from three-way and fourway exchanges receive higher transfers at competitive equilibrium, even when only two-way exchanges are feasible. Finally, this result is useful in the construction of a competitive equilibrium. (The proof is in the online Appendix, http://www.e-aer.org/data/june07/20051331_ app.pdf.)

PROPOSITION 4: Let $\mu$ be a competitive matching and $p \in \mathbb{R}^{|\mathcal{T}|}$ be a supporting competitive price. Then every incompatible pair on the short side of the market is matched with a pair on the long side of the market, and:

$$
\begin{aligned}
p_{\mathrm{AB}-\mathrm{O}} & \geq p_{\mathrm{A}-\mathrm{O}}>0, \\
p_{\mathrm{AB}-\mathrm{O}} \geq & p_{\mathrm{AB}-\mathrm{B}}>0, \\
p_{\mathrm{AB}-\mathrm{O}} \geq & p_{\mathrm{B}-\mathrm{O}} \geq p_{\mathrm{B}-\mathrm{A}}>0, \\
p_{\mathrm{AB}-\mathrm{O}} & \geq p_{\mathrm{AB}-\mathrm{A}} \geq p_{\mathrm{B}-\mathrm{A}}>0, \\
p_{\mathrm{X}-\mathrm{X}} & =0 \quad \text { for any } \\
& \mathrm{X}-\mathrm{X} \in\{\mathrm{O}-\mathrm{O}, \mathrm{A}-\mathrm{A}, \mathrm{B}-\mathrm{B}, \mathrm{AB}-\mathrm{AB}\}, \\
p_{\mathrm{X}-\mathrm{Y}}= & -p_{\mathrm{Y}-\mathrm{X}} \quad \text { for any } \quad \mathrm{X}-\mathrm{Y} \in \mathcal{L} .
\end{aligned}
$$

\section{B. Equilibrium Existence through Segregated and Pooled Markets}

Since $p_{\mathrm{X}-\mathrm{X}}=0$ for $\mathrm{X}-\mathrm{X} \in\{\mathrm{O}-\mathrm{O}, \mathrm{A}-\mathrm{A}, \mathrm{B}-\mathrm{B}$, $A B-A B\}$, compatible pairs of type $X-X$ remain unmatched, whereas incompatible pairs of type $\mathrm{X}-\mathrm{X}$ match with each other at competitive equilibria. Therefore, we can restrict our attention to the short and long sides of the market. Furthermore, Proposition 4 together with a balanced budget implies pairs of short-side types can be matched only with pairs of long-side types at competitive equilibria.

We will obtain competitive prices through a simple demand-supply analysis. To illustrate when and how markets for multiple types on the 


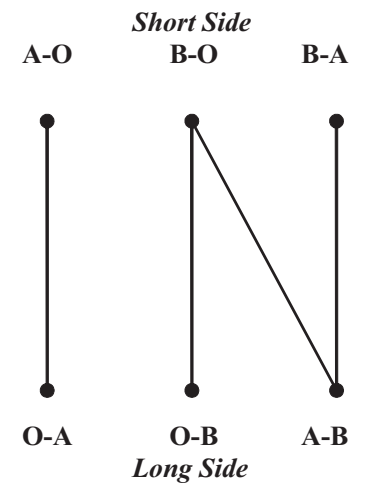

FIGURE 7

Notes: Mutual compatibility between the long and short sides of the market with three blood types $\mathrm{O}, \mathrm{A}$, and $\mathrm{B}$ under Assumptions 1, 2, and 3.

short side interact, we first consider a simpler case with only three blood types-O, A, B. The general case is intuitively similar but technically more involved. In this simpler model, there are nine types of pairs where types A-O, B-O, B-A are on the short side and O-A, O-B, $\mathrm{A}-\mathrm{B}$ are on the long side of the market. Mutual compatibility between the short side and the long side is given in Figure 7.

In the absence of blood-type $\mathrm{AB}$, type $\mathrm{A}-\mathrm{O}$ is mutually compatible with only type O-A on the long side, and similarly type O-A is mutually compatible with only type A-O on the short side. Therefore, pairs of these two types can be matched only with each other in a segregated A-O\&O-A market. Since $\#^{I}(\mathrm{~A}-\mathrm{O})<\#^{I}(\mathrm{O}-\mathrm{A})$ by Assumption 2, we can interpret type O-A pairs on the long side as demanders and type A-O pairs on the short side as suppliers in this segregated market. Moreover $p_{\mathrm{O}-\mathrm{A}}=-p_{\mathrm{A}-\mathrm{O}}$ by Proposition 4 at competitive equilibria and therefore we can interpret $S_{\mathrm{A}-\mathrm{O}}(p)=\#(\mathrm{~A}-\mathrm{O})(p)$ as the supply function of type A-O and $D_{\mathrm{O}-\mathrm{A}}(p)=\#(\mathrm{O}-\mathrm{A})(-p)$ as the demand function of type $\mathrm{O}-\mathrm{A}$. By assumption, \#(O-A)( $p)$ is continuous and strictly increasing in the interval $[-\bar{v}, 0]$ with $\#(\mathrm{O}-\mathrm{A})(0)=\#^{I}(\mathrm{O}-\mathrm{A})$ and $\#(\mathrm{O}-\mathrm{A})(-\bar{v})=0$. Equivalently, the demand function $D_{\mathrm{O}-\mathrm{A}}(p)=\#(\mathrm{O}-\mathrm{A})(-p)$ is continuous and strictly decreasing in the interval $[0, \bar{v}]$ with $D_{\mathrm{O}-\mathrm{A}}(0)=\#^{I}(\mathrm{O}-\mathrm{A})$ and $D_{\text {O-A }}(\bar{v})=0$. Again, by assumption, the sup-

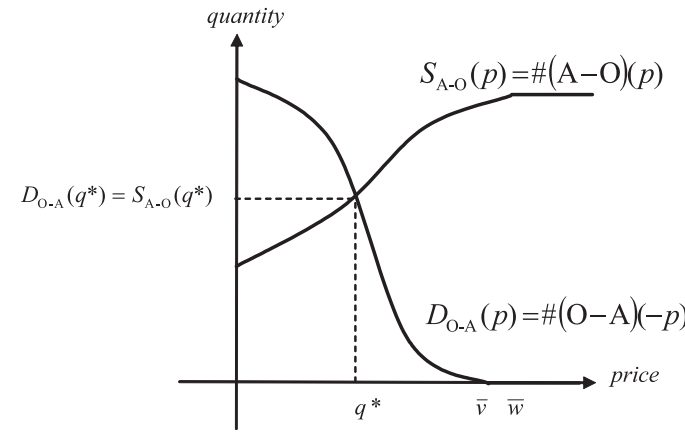

Figure 8. Pooled Market Equilibrium with A-O And O-A Type PAIRS

ply function $S_{\mathrm{A}-\mathrm{O}}(p)=\#(\mathrm{~A}-\mathrm{O})(p)$ is continuous and strictly increasing in the interval $[0, \bar{v}]$ with $S_{\mathrm{A}-\mathrm{O}}(0)=\#^{I}(\mathrm{~A}-\mathrm{O})<\#^{I}(\mathrm{O}-\mathrm{A})=$ $D_{\mathrm{O}-\mathrm{A}}(0)$. Hence, the demand and supply curves intersect at a unique market clearing price $q^{*} \in(0, \bar{v})$, where

$$
\underbrace{D_{\mathrm{O}-\mathrm{A}}\left(q^{*}\right)}_{=\#(\mathrm{O}-\mathrm{A})\left(-q^{*}\right)}=\underbrace{S_{\mathrm{A}-\mathrm{O}}\left(q^{*}\right)}_{=\#(\mathrm{~A}-\mathrm{O})\left(q^{*}\right)} .
$$

(See Figure 8.) Consequently, the market clearing prices for types $\mathrm{O}-\mathrm{A}, \mathrm{A}-\mathrm{O}$ is $p_{\mathrm{O}-\mathrm{A}}=-q^{*}$, $p_{\mathrm{A}-\mathrm{O}}=q^{*}$, and pairs of types $\mathrm{O}-\mathrm{A}$ with valuations at least $q^{*}$, are matched with pairs of types A-O with valuations at least $-q^{*}$ at competitive equilibria.

Since the short-side type B-O is mutually compatible with the long-side type A-B in addition to its opposite type $\mathrm{O}-\mathrm{B}$, the analysis is more involved for types $\mathrm{B}-\mathrm{O}$ and $\mathrm{B}-\mathrm{A}$ on the short side and their opposite types on the long side. First, consider a segregated market for types $\mathrm{B}-\mathrm{O}$ and $\mathrm{O}-\mathrm{B}$ with a market clearing price $r^{*}$ for type $\mathrm{B}-\mathrm{O}$, and a segregated market for types B-A and A-B with a market clearing price $s^{*}$ for type B-A. We have two cases to consider: Case 1: $r^{*} \geq s^{*}$. In this case pairs of the short-side type B-O have no interest in getting matched with pairs from the long-side type $\mathrm{A}-\mathrm{B}$, because the market clearing price in the segregated B-A\&A-B market is lower than that of the segregated $\mathrm{B}-\mathrm{O} \& \mathrm{O}-\mathrm{B}$ market. Hence, the three segregated markets A-O\&O-A, 
B-O\&O-B, B-A\&A-B determine competitive equilibria with competitive price

$$
\begin{array}{r}
\left(p_{\mathrm{O}-\mathrm{O}}, p_{\mathrm{O}-\mathrm{A}}, p_{\mathrm{O}-\mathrm{B}}, p_{\mathrm{A}-\mathrm{O}}, p_{\mathrm{A}-\mathrm{A}}, p_{\mathrm{A}-\mathrm{B}}, p_{\mathrm{B}-\mathrm{O}}, p_{\mathrm{B}-\mathrm{A}}, p_{\mathrm{B}-\mathrm{B}}\right) \\
=\left(0,-q^{*},-r^{*}, q^{*}, 0,-s^{*}, r^{*}, s^{*}, 0\right) .
\end{array}
$$

Case 2: $r^{*}<s^{*}$. In this case the price in the segregated $\mathrm{B}-\mathrm{O} \& \mathrm{O}-\mathrm{B}$ market is too low and pairs of short-side type $\mathrm{B}-\mathrm{O}$, who are compatible with both types O-B and A-B, are not maximizing utility since they all prefer a monetary transfer of $s^{*}$ to $r^{*}$. (Also recall from Proposition 4 that $p_{\mathrm{B}-\mathrm{O}} \geq p_{\mathrm{B}-\mathrm{A}}$ must hold at competitive equilibria.) In this case, we will have a pooled market with pairs from short-side types B-O and $\mathrm{B}-\mathrm{A}$ as suppliers and pairs from long-side types $\mathrm{O}-\mathrm{B}$ and $\mathrm{A}-\mathrm{B}$ as demanders. In the pooled market, there exists a unique price $t^{*} \in\left(r^{*}, s^{*}\right)$, where

$$
\begin{aligned}
& D_{\mathrm{O}-\mathrm{B}}\left(t^{*}\right)+D_{\mathrm{A}-\mathrm{B}}\left(t^{*}\right) \\
& =\#(\mathrm{O}-\mathrm{B})\left(-t^{*}\right) \quad=\#(\mathrm{~A}-\mathrm{B})\left(-t^{*}\right) \\
& \begin{array}{c}
=S_{\mathrm{B}-\mathrm{O}}\left(t^{*}\right)+\underset{ }{=\#(\mathrm{~B}-\mathrm{O})\left(t^{*}\right)} \quad S_{\mathrm{B}-\mathrm{A}}\left(t^{*}\right) \\
=\#(\mathrm{~B}-\mathrm{A})\left(t^{*}\right)=\#(\mathrm{~B}-\mathrm{A})
\end{array} .
\end{aligned}
$$

(See Figure 9.) The market clearing price $t^{*}$ is in the open interval $\left(r^{*}, s^{*}\right)$ because:

- The excess supply function $S_{\mathrm{B}-\mathrm{O}}(p)-D_{\mathrm{O}-\mathrm{B}}(p)=$ $\#(\mathrm{~B}-\mathrm{O})(p)-\#(\mathrm{O}-\mathrm{B})(-p)$ in the segregated market $\mathrm{B}-\mathrm{O} \& \mathrm{O}-\mathrm{B}$ has a value of 0 at $p=r^{*}$ and it is continuously and strictly increasing in the interval $[0, \bar{v}]$ (and hence in the interval $\left[r^{*}, s^{*}\right]$ as well); and

- The excess demand function $D_{\mathrm{A}-\mathrm{B}}(p)-$ $S_{\mathrm{B}-\mathrm{A}}(p)=\#(\mathrm{~A}-\mathrm{B})(-p)-\#(\mathrm{~B}-\mathrm{A})(p)$ in the segregated market B-A\&A-B has a value of 0 at $p=s^{*}>r^{*}$ and it is continuously and strictly decreasing in the interval $[0, \bar{v}]$ (and hence in the interval $\left[r^{*}, s^{*}\right]$ as well).

Therefore, in this case the segregated market A-O\&O-A together with the pooled market B-O,B-A\&O-B,A-B determine competitive equilibria with competitive price

$\left(p_{\mathrm{O}-\mathrm{O}}, p_{\mathrm{O}-\mathrm{A}}, p_{\mathrm{O}-\mathrm{B}}, p_{\mathrm{A}-\mathrm{O}}, p_{\mathrm{A}-\mathrm{A}}, p_{\mathrm{A}-\mathrm{B}}, p_{\mathrm{B}-\mathrm{O}}, p_{\mathrm{B}-\mathrm{A}}, p_{\mathrm{B}-\mathrm{B}}\right)$

$$
=\left(0,-q^{*},-t^{*}, q^{*}, 0,-t^{*}, t^{*}, t^{*}, 0\right) .
$$

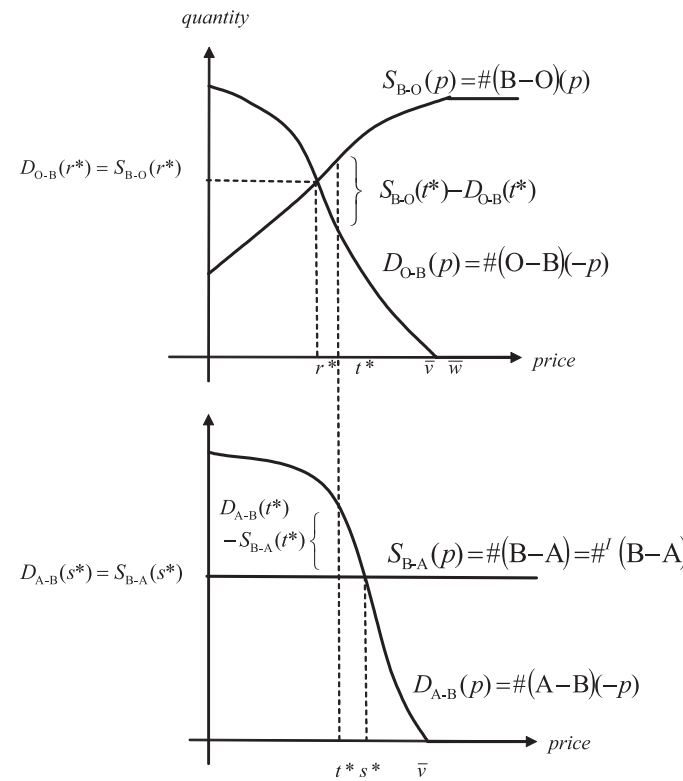

$$
S_{\mathrm{B}-\mathrm{O}}\left(t^{*}\right)-D_{\mathrm{O}-\mathrm{B}}\left(t^{*}\right)=D_{\mathrm{A}-\mathrm{B}}\left(t^{*}\right)-S_{\mathrm{B}-\mathrm{A}}\left(t^{*}\right)
$$

FIGURE 9

Notes: Pooled market equilibrium with B-O, O-B, B-A, and $\mathrm{A}-\mathrm{B}$ type pairs when the market clearing price in segregated B-A\&A-B market is higher than in segregated B-O\&O-B market.

This establishes the existence of a competitive equilibrium for the simple case with three blood types $\mathrm{O}, \mathrm{A}, \mathrm{B}$. The proof for the general case is in the online Appendix.

THEOREM 2: A competitive equilibrium exists in the kidney-exchange model with monetary transfers.

\section{Concluding Remarks}

This paper has two themes. The first is intensely practical and concerns the infrastructure that needs to be prepared to conduct kidney exchange among incompatible patient-donor pairs efficiently. The second is more general and concerns the role of markets in facilitating exchange, even in the absence of a medium of exchange, particularly when exchange involves indivisible goods whose types determine the feasibility of exchange. Taken together, these two points of view also shed some light on how 
the emerging discipline of market design will bring new kinds of theoretical as well as empirical questions to attention.

On the practical side, we have shown why it will be important to develop the infrastructure to identify and to perform three-way as well as two-way kidney exchanges, since the efficient utilization of $\mathrm{O}$ donors often requires three-way exchanges. Although the identification of maximal two- and three-way exchanges is a computationally hard problem ${ }^{15}$ (unlike the identification of maximal two-way exchanges; Roth, Sönmez, and Ünver 2005a), it appears that instances of practical size can be readily solved with conventional integer programming software. And, while performing three-way exchanges requires six simultaneous surgeries, this will often be feasible, particularly when the patients are at different transplant centers. It seems likely that the most usual logistical arrangement will be for the donor to travel to the designated patient's transplant center. So, for example, in the case of a three-way exchange in which each patient is at a different hospital, each of three hospitals will be performing only two surgeries, which they would be required to perform in any live-donor kidney transplant. ${ }^{16}$ As Proposition 2 explains, and Table 2 demonstrates, the gains from including the possibility of three-way exchange are substantial, and substantially greater than the further marginal gains from four-way exchange (Proposition 3 and Table 2). Thus, at least initially we will be searching for two- and three-way exchanges in the New England Program for Kidney Exchange, and other regional exchanges.

Of course, many of the gains will come sim-

\footnotetext{
${ }^{15}$ Personal communication, Michel Goemans and Kevin Cheung. See also some related work of Peter Biro and Katarina Cechlarova (2006) and Cechlarova and Vladimir Lacko (2006).

${ }^{16}$ The logistics of three-way exchanges will remain more difficult than two-way exchanges, even when three hospitals are involved. A three-way exchange involves scheduling surgery for six patients, all of whom must be compatible and ready for surgery at the same time, and will consequently have higher probability of being delayed or cancelled than a two-way exchange that involves only four patients. But even in circumstances in which three-way exchanges are significantly more difficult to complete than two-way exchanges, some patients will be able to be transplanted only through three-way exchange.
}

ply from making the market thick, by assembling a database of incompatible patient donor pairs who are interested in exchange. Efforts are underway to create a national clearinghouse for kidney exchange in the United States. The potential impact of a national kidney exchange clearinghouse seems to be large. For example, in South Korea and in the Netherlands, although no attention is paid to optimization, more than 10 percent of all live kidney donations are attributed to (two-way) kidney exchanges through national databases (cf. Kiil Park 2004; Marry de Klerk et al. 2005). ${ }^{17}$

\section{A. M\&Ms: Money and Markets}

More generally, this paper is about how markets facilitate exchange, and how the nature of transactions determines which exchanges are efficient. Theorem 1 shows that the relationship between the size of efficient exchanges and the number of blood types that we see in kidney exchange generalizes to a model of type-compatible exchange. Even in large markets, the maximum size exchange needed for efficiency may be small, if the number of types is small. And Proposition 4 and Theorem 2 show that relative prices would reflect both the scarcity and compatibility of different types at a competitive equilibrium.

Jevons (1876) famously suggests that the primary difficulties with barter arise from the absence of, and can be solved by the introduction of, a medium of exchange. We argue that many of the problems that Jevons identifies as resulting from an absence of money would continue to be problems (even with money) in the absence of a sufficiently thick market, and that many of the benefits Jevons sees as flowing from the presence of money result at least in part from the presence of a market. Kidney exchange allows us to see which of the market effects can still be achieved in the absence of money.

We show that a thick market organized by a clearinghouse provides many of the benefits

\footnotetext{
${ }^{17}$ A comparable number would mean at least 650 transplants could be conducted per year through kidney exchanges in the United States.
} 
that Jevons attributed to the presence of a medium of exchange. Table 2 shows that about 60 percent of the incompatible pairs can benefit in this way, with those that cannot being the pairs on the long side of the market, primarily Oblood-type patients with A or B donors. To benefit these patients it would be necessary to increase the supply of O-type donors (and this would be one effect of allowing compatible pairs to participate in exchanges).

Of course, these benefits, achieved without the use of money, accrue only to those patients who have a willing kidney donor. In contrast, if the legal/ethical/social objections to a fully monetized market were to be resolved, and money could be exchanged to recruit donors from the general population, then it would presumably be possible to arrange transplants for a high percentage of all patients in need of one.

\section{B. Market Design and Market Clearing}

As economists are more frequently called upon to design markets, ${ }^{18}$ and not merely to study them at arm's length, there will be new opportunities for understanding how markets work, and what obstacles they face in achieving efficient allocation.

Kidney exchange, in the context of the legal prohibitions on the buying and selling of organs, gives us a chance to look closely at the exchange of indivisible goods, without a medium of exchange, in an environment in which the structure of efficient exchange can be analyzed. One of the main contributions that a centralized clearinghouse can make in this context is to establish a sufficiently thick market so that double and triple coincidences of wants can be identified and consummated.

In general, clearinghouses seem to be in most demand in markets that have suffered failures with respect to the thickness of the market, or from congestion in making and processing enough offers; or that have incentive problems that make it unsafe for participants to provide information needed for efficient allocation. For example, clearinghouses recently designed for

\footnotetext{
${ }^{18}$ Cf., e.g., Paul Milgrom (2004), Roth (2002), and Robert B. Wilson (2002).
}

other markets in which monetary transfers are considered inappropriate have involved the allocation of public school places in New York City (where the clearinghouse solved a congestion problem), and in Boston, where the existing allocation system had an incentive problem (see Atila Abdulkadiroğlu and Sönmez 2003; Abdulkadiroğlu, Parag A. Pathak, and Roth 2005; and Abdulkadiroğlu et al. 2005). Clearinghouses are also used in markets in which monetary wages are entirely appropriate, such as the labor markets for new doctors (see, e.g., Roth 1984; Roth and Elliot Peranson 1999), and for medical specialists of various sorts (see, e.g., Muriel Niederle and Roth 2005). ${ }^{19}$ And there has been recent attention to how decentralized markets deal well or badly with some of the same problems that clearinghouses can be used to solve (in, e.g., the markets for college admissions and financial aid, law clerks, gastroenterologists, psychologists, collectables, etc.). ${ }^{20}$

Viewed in this light, the present study is part of the growing investigation into how markets are, and need to be, designed to achieve efficiency, taking into account the particular constraints they face. This line of work, which is given focus by the demand for practical designs for particular markets, directs our attention to the many still poorly understood details of market clearing, in a way that can, in the long term, only deepen our understanding of how markets work in general.

\section{Appendix: Integer Programming Formulation}

We use different techniques to find the maximal set of exchanges in the simulations. To explain this, we introduce some additional notation. Let $N$ denote the set of patient-donor

\footnotetext{
${ }^{19}$ For discussions of wage setting in centralized clearinghouses, see Alexander S. Kelso, Jr., and Vincent P. Crawford (1982), Roth and Marilda Sotomayor (1990), Jeremy I. Bulow and Jonathan Levin (2006), Crawford (2005), John Hatfield and Milgrom (2005), Kojima (2007), Niederle (2007), and Siva Anantham and Jennifer Stack (2006).

${ }^{20}$ See, e.g., Christopher N. Avery, Andrew Fairbanks, and Richard Zeckhauser (2003); Avery et al. (2001); Ernan Haruvy, Roth, and Ünver (2006); Niederle and Roth (2003, 2004); Roth and Xiaolin Xing (1997); and Axel Ockenfels and Roth (2002).
} 
pairs available for exchange. We give the explicit formulation of finding the maximal number of patients who can benefit from two-way and up to $k$-way exchanges for any number $k$ such that $|N| \geq k \geq 2$. For each pair $i \in N$, let $P_{i}$ denote the patient and $D_{i}$ denote the donor.

Suppose $E=\left(P_{i_{1}}-D_{i_{1}}, \ldots, P_{i_{k}}-D_{i_{k}}\right)$ denotes a $k$-way exchange in which pairs $i_{1}, \ldots, i_{k}$ participate. Let $|E|$ be the number of transplants possible under $E$; hence we have $|E|=k$.

Let $\mathcal{F}^{k}$ be the set of feasible two-way through $k$-way exchanges possible among the pairs in $N$. For any pair $i$, let $\mathcal{E}^{k}(i)$ denote the set of exchanges in $\mathcal{E}^{k}$ such that pair $i$ can participate. Let $\boldsymbol{x}=\left(x_{E}\right)_{E \in \mathcal{F}^{k}}$ be a vector of 0's and 1's such that $x_{E}=1$ denotes that exchange $E$ is going to be conducted, and $x_{E}=0$ denotes that exchange $E$ is not going to be conducted. Our problem of finding a maximal set of patients who will benefit from two-way, ..., and $k$-way exchanges is given by the following integer program:

$$
\begin{gathered}
\max _{x} \sum_{E \in \mathcal{F}^{k}}|E| x_{E} \\
\text { subject to } \\
x_{E} \in\{0,1\} \quad \forall E \in \mathcal{F}^{k}, \\
\sum_{E \in \mathcal{F}^{k}(i)} x_{E} \leq 1 \quad \forall i \in N .
\end{gathered}
$$

This problem is solved using Edmonds's (1965) algorithm for $k=2$ (i.e., only for twoway exchanges) in polynomial time. For $k \geq 3$, however, this problem is NP-complete. ${ }^{21}$ Therefore, we use integer programming software for $k \geq 3$.

We also formulate the following version of the integer programming problem, which does not require ex ante construction of the sets $\mathcal{F}^{k}$.

Let $\boldsymbol{C}=\left[c_{i, j}\right]_{i \in N, j \in N}$ be a matrix of 0's and 1's such that if Patient $P_{i}$ is compatible with Donor $D_{j}$ we have $c_{i, j}=1$ and if patient $P_{i}$ is not compatible with donor $D_{j}$ we have $c_{i, j}=0$. Let $\boldsymbol{X}=\left[x_{i, j}\right]_{i \in N, j \in N}$ be the assignment matrix of

\footnotetext{
${ }^{21}$ The observation that the mixed two- and three-way problem is NP complete was made by Kevin Cheung and Michel Goemans (personal communication).
}

0 's and 1's such that $x_{i, j}=1$ denotes that patient $P_{i}$ receives a kidney from donor $D_{j}$ and $x_{i, j}=0$ denotes that patient $P_{i}$ does not receive a kidney from donor $D_{j}$ under the proposed assignment $\boldsymbol{X}$. We solve the following integer program to find a maximal set of two-way, ..., and $k$-way exchanges:

$$
\max _{\boldsymbol{X}} \sum_{i \in N, j \in N} x_{i, j}
$$

subject to

$$
\begin{gathered}
x_{i, j} \in\{0,1\} \quad \forall i, j \in N, \\
x_{i, j} \leq c_{i, j} \quad \forall i, j \in N, \\
\sum_{j \in N} x_{i, j} \leq 1 \quad \forall i \in N, \\
\sum_{j \in N} x_{i, j}=\sum_{j \in N} x_{j, i} \quad \forall i \in N, \\
x_{i_{1}, i_{2}}+x_{i_{2}, i_{3}}+\cdots+x_{i_{k}, i_{k+1}} \leq k-1 \\
\forall\left\{i_{1}, i_{2}, \ldots, i_{k}, i_{k+1}\right\} \subseteq N .
\end{gathered}
$$

A solution of this problem determines a maximal set of patients who can benefit from twoway, $\ldots$, and $k$-way exchanges for any $k<|N|$. A maximal set of patients who can benefit from unrestricted exchanges is found by setting $k=|N|$. In this case, Constraint 6 becomes redundant. We use this formulation to find the maximal set of unrestricted exchanges in the simulations. For other cases, we use the earlier formulation.

\section{REFERENCES}

Abdulkadiroğlu, Atila, Parag A. Pathak, and Alvin E. Roth. 2005. "The New York City High School Match." American Economic Review, 95(2): 364-67.

Abdulkadiroğlu, Atila, Parag A. Pathak, Alvin E. Roth, and Tayfun Sönmez. 2005. "The Boston Public School Match." American Economic Review, 95(2): 368-71.

Abdulkadiroğlu, Atila, and Tayfun Sönmez. 2003. "School Choice: A Mechanism Design 
Approach." American Economic Review, 93(3): 729-47.

Anantham, Siva, and Jennifer Stack. 2006. "Wage Formation under Early Contracting." Unpublished.

Avery, Christopher N., Andrew Fairbanks, and Richard Zeckhauser. 2003. The Early Admissions Game: Joining the Elite. Cambridge, MA: Harvard University Press.

Avery, Christopher N., Christine M. Jolls, Richard A. Posner, and Alvin E. Roth. 2001. "The Market for Federal Judicial Law Clerks." University of Chicago Law Review, 68: 793-902.

Becker, Gary S., and Julio J. Elias. Forthcoming. "Introducing Incentives in the Market for Live and Cadaveric Organ Donations." Journal of Economic Perspectives.

Biro, Peter, and Katarina Cechlarova. 2006. "Inapproximability of the Kidney Exchange Problem." Unpublished.

Bulow, Jeremy, and Jonathan Levin. 2006. "Matching and Price Competition." American Economic Review, 96(3): 652-68.

Cechlarova, Katarina, and Vladimir Lacko. 2006. "The Kidney Exchange Problem: How Hard Is It to Find a Donor?" Unpublished.

Crawford, Vincent P. Forthcoming. "The Flexible-Salary Match: A Proposal to Increase the Salary Flexibility of the National Resident Matching Program." Journal of Economic Behavior and Organization.

Delmonico, Francis L. 2004. "Exchanging Kidneys: Advances in Living-Donor Transplantation." The New England Journal of Medicine, 350(18): 1812-14.

Edmonds, Jack. 1965. "Paths, Trees, and Flowers." Canadian Journal of Mathematics, 17: 449-67.

Epstein, Richard A. 2006. "The Human and Economic Dimensions of Altruism." Paper Presented at the President's Council on Bioethics, April 20-21, Washington, DC.

Gjertson, David W., and J. Michael Cecka. 2000. "Living Unrelated Donor Kidney Transplantation," Kidney International, 58(2): 491-99.

Hatfield, John William, and Paul R. Milgrom. 2005. "Matching with Contracts." American Economic Review, 95(4): 913-35.

Haruvy, Ernan, Alvin E. Roth, and M. Utku Ünver. 2006. "The Dynamics of Law Clerk Matching: An Experimental and Computa- tional Investigation of Proposals for Reform of the Market." Journal of Economic Dynamics and Control, 30(3): 457-86.

Jevons, William S. 1876. Money and the Mechanism of Exchange. New York: D. Appleton and Company. http://www.econlib.org/library/ YPDBooks/Jevons/jvnMME.html (accessed April 30, 2006).

Kelso, Alexander S., Jr., and Vincent P. Crawford. 1982. "Job Matching, Coalition Formation, and Gross Substitutes." Econometrica, 50(6): 1483-1504.

Klerk, Marry de, Karin M. Keizer, Frans H. J. Claas, Marin Witvliet, Bernadette J. J. M. Haase-Kromwijk, and Willem Weimar. 2005. "The Dutch National Living Donor Kidney Exchange Program." American Journal of Transplantation, 5(9): 2302-05.

Kojima, Fuhito. 2007. "Matching and Price Competition: Comment." American Economic Review, 97(3): 1027-31.

Lucan, M., Rotariu, D. Neculoiu, and G. Iacob. 2003. "Kidney Exchange Program: A Viable Alternative in Countries with Low Rate of Cadaver Harvesting." Transplantation Proceedings, 35(3): 933-34.

Milgrom, Paul. 2004. Putting Auction Theory to Work. Churchill Lectures in Economics. Cambridge: Cambridge University Press.

Montgomery, Robert A., Andrea A. Zachary, Loyd E. Ratner, Dorry L. Segev, Janet M. Hiller, Julie Houp, Mathew Cooper et al. 2005. "Clinical Results from Transplanting Incompatible Live Kidney Donor/Recipient Pairs Using Kidney Paired Donation." The Journal of American Medical Association, 294(13): 165563.

Nadel, Mark S., and Carolina A. Nadel. 2005. "Using Reciprocity to Motivate Organ Donations." Yale Journal of Health Policy, Law, and Ethics. 5(1): 293-325.

Niederle, Muriel. Forthcoming. "Competitive Wages in a Match with Ordered Contracts." American Economic Review.

Niederle, Muriel, and Alvin E. Roth. 2003. "Unraveling Reduces Mobility in a Labor Market: Gastroenterology with and without a Centralized Match." Journal of Political Economy, 111(6): 1342-52.

Niederle, Muriel, and Alvin E. Roth. 2004. "Market Culture: How Norms Governing Explod- 
ing Offers Affect Market Performance." Unpublished.

Niederle, Muriel, and Alvin E. Roth. 2005. "The Gastroenterology Fellowship Market: Should There Be a Match?" American Economic Review, 95(2): 372-5.

Opelz, Gerhard. 1997. "Impact of HLA Compatibility on Survival of Kidney Transplants from Unrelated Live Donors." Transplantation, 64(10): 1473-75.

Opelz, Gerhard, for the Collaborative Transplant Study. 1998. "HLA Compatibility and Kidney Grafts from Unrelated Live Donors." Transplantation Proceedings, 30(3): 704-05.

Park, Kiil, Jang Moon, Soon Kim, and Yu Suen Kim. 2004. "Exchange Living-Donor Kidney Transplantation: Diminution of Donor Organ Shortage." Transplantation Proceedings, 36(10): 2949-51.

Quint, Thomas, and Jun Wako. 2004. "On Houseswapping, the Strict Core, Segmentation, and Linear Programming." Mathematics of Operations Research, 29(4): 861-77.

Roth, Alvin E. 1984. "The Evolution of the Labor Market for Medical Interns and Residents: A Case Study in Game Theory." Journal of Political Economy, 92(6): 991-1016.

Roth, Alvin E. 2002. "The Economist as Engineer: Game Theory, Experimentation, and Computation as Tools for Design Economics." Econometrica, 70(4): 1341-78.

Roth, Alvin E. Forthcoming. "Repugnance as a Constraint on Market Design." Journal of Economic Perspectives.

Roth, Alvin E., and Axel Ockenfels. 2002. "LastMinute Bidding and the Rules for Ending Second-Price Auctions: Evidence from eBay and Amazon Auctions on the Internet." American Economic Review, 92(4): 1093-1103.

Roth, Alvin E., and Elliott Peranson. 1999. "The Redesign of the Matching Market for American Physicians: Some Engineering Aspects of Economic Design." American Economic Review, 89(4): 748-80.

Roth, Alvin E., and Andrew Postlewaite. 1977. "Weak versus Strong Domination in a Market with Indivisible Goods." Journal of Mathematical Economics, 4(2): 131-37.

Roth, Alvin E., Tayfun Sönmez, and M. Utku Ünver. 2004. "Kidney Exchange." Quarterly Journal of Economics, 119(2): 457-88.
Roth, Alvin E., Tayfun Sönmez, and M. Utku Ünver. 2005a. "Pairwise Kidney Exchange." Journal of Economic Theory, 125(2): 151-88.

Roth, Alvin E., Tayfun Sönmez, and M. Utku Ünver. 2005b. "A Kidney Exchange Clearinghouse in New England." American Economic Review, 95(2): 376-80.

Roth, Alvin E., Tayfun Sönmez, M. Utku Ünver, Francis L. Delmonico, and Susan L. Saidman. 2006. "Utilizing List Exchange and Undirected Good Samaritan Donation through 'Chain' Paired Kidney Exchanges." American Journal of Transplantation, 6(11): 2694-2705.

Roth, Alvin E., and Marilda A. Oliveira Sotomayor. 1990. Two-Sided Matching: A Study in Game-Theoretic Modeling and Analysis. Econometric Society Monographs No. 18. Cambridge: Cambridge University Press.

Roth, Alvin E., and Xiaolin Xing. 1997. "Turnaround Time and Bottlenecks in Market Clearing: Decentralized Matching in the Market for Clinical Psychologists." Journal of Political Economy, 105(2): 284-329.

Saidman, Susan L., Alvin E. Roth, Tayfun Sönmez, M. Utku Ünver, and Francis L. Delmonico. 2006. "Increasing the Opportunity of Live Kidney Donation by Matching for Two and Three Way Exchanges." Transplantation, 81(5): 773-82.

Segev, Dorry L., Sommer E. Gentry, Daniel S. Warren, Brigitte Reeb, and Robert A. Montgomery. 2005. "Kidney Paired Donation and Optimizing the Use of Live Donor Organs." The Journal of the American Medical Association, 293(15): 1883-90.

Shapley, Lloyd, and Herbert Scarf. 1974. "On Cores and Indivisibility." Journal of Mathematical Economics, 1(1): 23-37.

Terasaki, Paul I., David W. Gjertson, and J. Michael Cecka. 1998. "Paired Kidney Exchange Is Not a Solution to ABO Incompatibility." Transplantation, 65(2): 291.

Ünver, M. Utku. 2007. "Dynamic Kidney Exchange." Unpublished.

Wilson, Robert B. 2002. "Architecture of Power Markets." Econometrica, 70(4): 1299-1340.

Zenios, Stefanos, E. Steve Woodle, and Laine Friedman Ross. 2001. "Primum non nocere: Avoiding Harm to Vulnerable Wait List Candidates in an Indirect Kidney Exchange." Transplantation, 72(4): 648-54. 